\title{
Editing of Serotonin 2C Receptor mRNA in the Prefrontal Cortex Characterizes High-Novelty Locomotor Response Behavioral Trait
}

\author{
Stella Dracheva*,1,2, Rebecca Lyddon², Kevin Barley², Sue M Marcus², Yasmin L Hurd ${ }^{1,2}$ and \\ William M Byne ${ }^{1,2}$ \\ 'James J Peters Veterans Affairs Medical Center, Bronx, NY, USA; ${ }^{2}$ Department of Psychiatry, Mount Sinai School of Medicine, New York, NY, \\ USA
}

\begin{abstract}
Serotonin $2 \mathrm{C}$ receptor $\left(5-\mathrm{HT}_{2} \mathrm{C}\right.$ ) exerts a major inhibitory influence on dopamine (DA) neurotransmission within the mesocorticolimbic DA pathway that is implicated in drug reward and goal-directed behaviors. $5-H_{2} T_{2} R$ pre-mRNA undergoes adenosine-to-inosine editing, generating numerous receptor isoforms in brain. As editing influences $5-H_{2} T_{2} R$ activity, individual differences in editing might influence dopaminergic function and, thereby, contribute to interindividual vulnerability to drug addiction. Liability to drug-related behaviors in rats can be predicted by their level of motor activity in response to a novel environment. Rats with a high locomotor response (high responders; HRs) exhibit enhanced acquisition and maintenance of drug self-administration compared to rats with a low response (low responders; LRs). We here examined $5-H T_{2} C R$ mRNA editing and expression in HR and LR phenotypes to investigate the relationship between $5-\mathrm{HT}_{2} \mathrm{C}$ function and behavioral traits relevant to drug addiction vulnerability. Three regions of the mesocorticolimbic circuitry (ventral tegmental area (VTA), nucleus accumbens (NuAc) shell, and medial prefrontal cortex (PFC)) were examined. 5- $\mathrm{HT}_{2} \mathrm{C}$ mRNA expression and editing were significantly higher in the NuAc shell compared with both the PFC and VTA, implying significant differences in function (including constitutive activity) among $5-\mathrm{HT}_{2} \mathrm{C}$ neuronal populations within the circuitry. The regional differences in editing could, at least in part, arise from the variations in expression levels of the editing enzyme, ADAR2, and/or from the variations in the ADAR2/ADARI ratio observed in the study. No differences in the 5-HT2CR expression were detected between the behavioral phenotypes. However, editing was higher in the PFC of HRs vs LRs, implicating this region in the pathophysiology of drug abuse liability.

Neuropsychopharmacology (2009) 34, 2237-225I; doi:I0. I038/npp.2009.5I; published online 3 June 2009
\end{abstract}

Keywords: serotonin $2 \mathrm{C}$ receptor; mRNA editing; drug addiction; rat; high and low responders; prefrontal cortex

\section{INTRODUCTION}

Humans and animals show wide interindividual differences in the susceptibility to drug addiction (de Wit et al, 1986; Piazza et al, 1998), with notable inherent dissimilarities in the reinforcing effects of addictive drugs (Volkow et al, 2002). The mesoaccumbal and mesocortical dopamine (DA) pathways, which originate in the ventral tegmental area (VTA) and terminate in the nucleus accumbens $(\mathrm{NuAc})$ and prefrontal cortex (PFC), respectively, are most widely implicated in drug reward and goal-directed behaviors (Everitt and Robbins, 2005). Serotonin (5-HT) exerts a major modulatory influence on DA neurotransmission within these pathways via multiple 5-HT receptor subtypes

*Correspondence: Dr S Dracheva, Psychiatry Research (4F-02), Bronx VA Medical Center, I 30 West Kingsbridge Road, Bronx, NY I0468, USA, Tel: 718584 9000, Fax: 7183659622 ,

E-mail: Stella.Dracheva@mssm.edu

Received 30 January 2009; revised 6 April 2009; accepted 22 April 2009
(Roth, 1994). Among them, the 2C receptor subtype $\left(5-\mathrm{HT}_{2 \mathrm{C}} \mathrm{R}\right)$ is of particular importance (Giorgetti and Tecott, 2004). This receptor is localized in brain regions containing both DA cell bodies and their terminations, where it modulates DA-dependent behavioral and neurochemical effects of a variety of addictive drugs (Berg et al, 2008). Numerous studies have shown that the systemic administration of $5-\mathrm{HT}_{2 \mathrm{C}} \mathrm{R}$ agonists inhibits the rewarding and psychomotor-stimulant effects of cocaine, amphetamine, nicotine, and ethanol, whereas $5-\mathrm{HT}_{2 \mathrm{C}} \mathrm{R}$ antagonists potentiate these effects (Grottick et al, 2001; Fletcher et al, 2002; Tomkins et al, 2002). In line with these behavioral data, $5-\mathrm{HT}_{2 \mathrm{C}} \mathrm{R}$ exerts an inhibitory influence on both tonic and phasic DA neuron firing. Specifically, the basal and drug-stimulated firing rate of DA neurons in the VTA, as well as DA release at their terminals, is increased by the administration of $5-\mathrm{HT}_{2 \mathrm{C}} \mathrm{R}$ antagonists and decreased by the administration of receptor agonists (Gobert et al, 2000; Di Giovanni et al, 2002; Di Matteo et al, 2004; Navailles et al, 2004). 
$5-\mathrm{HT}_{2 \mathrm{C}} \mathrm{R}$ is the only known G-protein-coupled receptor whose pre-mRNA undergoes adenosine-to-inosine (A-to-I) editing (Burns et al, 1997; Werry et al, 2008). This editing is catalyzed by enzymes termed adenosine deaminases that act on RNA (ADAR1 and ADAR2) (Bass, 2002; Schmauss and Howe, 2002; Valente and Nishikura, 2005). The ADARs can modify one or more of five closely spaced adenosine residues (named A, B, E, C, and D editing sites) on the receptor mRNA. These five adenosine residues are spread among three triplet codons within a sequence that encodes the putative second intracellular domain of the $5-\mathrm{HT}_{2 \mathrm{C}} \mathrm{R}$ protein - a region thought to be important for G-protein coupling (Moro et al, 1993). As inosine is read as guanosine by the translational machinery, $5-\mathrm{HT}_{2 \mathrm{C}} \mathrm{R}$ mRNA editing can alter the coding potential of the three codons, generating up to 32 different mRNA variants and, consequently, up to 24 different protein isoforms. Previous in vitro studies indicated that RNA editing has a dramatic impact on the functional characteristics of $5-\mathrm{HT}_{2 \mathrm{C}} \mathrm{R}$. For example, compared with the non-edited receptor (INI), the two fully edited receptor isoforms (VSV and VGV) exhibit decreased potency, ligand-independent (constitutive) activity, agonist affinity, and internalization (Niswender et al, 1999; Herrick-Davis et al, 1999; Fitzgerald et al, 1999; Wang et al, 2000; Berg et al, 2001; Quirk et al, 2001; Marion et al, 2004). A mixture of differently edited and non-edited $5-\mathrm{HT}_{2 \mathrm{C}} \mathrm{R}$ mRNAs has been detected in both human and animal brains (Burns et al, 1997; Niswender et al, 2001). Individual differences in editing might, therefore, lead to differences in $5-\mathrm{HT}_{2 \mathrm{C}} \mathrm{R}$ function that could, in turn, influence dopaminergic function and contribute to interindividual vulnerability to drug addiction.

Variations in the liability to drug abuse-related behavior have been shown to occur naturally in outbred strains of rats. Moreover, liability to drug intake behavior is highly correlated with an animal's level of motor activity in stressful situations, such that drug self-administration as well as other behavioral and neurochemical responses to a psychostimulant can be predicted by the level of motor activity in response to a novel environment. Rats with a high locomotor response (high responders; HRs) have been well documented to exhibit enhanced acquisition and maintenance of drug self-administration and other drugrelated behaviors compared with rats with a low response to the novel context (low responders; LRs) (Piazza et al, 1989; Pierre and Vezina, 1997). In this study, we examined $5-\mathrm{HT}_{2 \mathrm{C}} \mathrm{R}$ editing and related mRNA transcripts in HR and LR animals to draw inferences regarding the relationship between $5-\mathrm{HT}_{2 \mathrm{C}} \mathrm{R}$ editing and behavioral traits relevant to drug addiction vulnerability. Three regions of the mesocorticolimbic DA pathway (VTA, NuAc shell, and medial PFC) were examined. In addition to region-specific variations in $5-\mathrm{HT}_{2 \mathrm{C}} \mathrm{R}$ mRNA editing common to both phenotypes, increased editing was seen in the PFC of HRs compared with LRs.

\section{METHODS}

\section{Animal Housing and Behavioral Experiments}

Six-week-old male Sprague Dawley rats $(N=104$; Taconic $)$ were processed in two sets of 52 animals each; the two series were separated by approximately 4 weeks. The animals were housed individually, maintained on 12-h dark/light cycle with food and water available ad libitum, and were allowed 2 weeks to acclimate to the animal room before behavioral assessment. To determine the behavioral phenotype, rats were screened for locomotor response to novelty in open-field apparatuses (VersaMax, Accuscan Instruments) for a $1 \mathrm{~h}$ period as previously described (Marinelli and White, 2000). Each set of 52 animals was screened over 5 consecutive days at the same time of the day (between 1100 and 1300 hours). All experiments were done in compliance with the Institutional Animal Care and Use Committee.

\section{Tissue Sampling with Laser Capture Microdissection}

Tissue preparation. One week after the end of behavioral testing, animals designated as HRs or LRs were killed by decapitation. Brains were removed, immediately frozen on dry ice, and subsequently sectioned serially in the coronal plane at a thickness of $20 \mu \mathrm{m}$ in a cryostat (Leica CM 1900; Leica Microsystems Inc., Bannockburn, IL). For anatomical localization, the first two of each series of 10 sections were mounted onto regular glass slides, stained with thionin, and coverslipped to serve as reference sections. The next set of eight sections was mounted onto penfoil polymer (PEN) microdissection slides and stored at $-80^{\circ} \mathrm{C}$ until use. Every effort was made to maintain a near-surgical aseptic setting when handling brains, slides, and tissue sections to protect against RNA degradation by RNAses.

Anatomical parcellation. Three brain regions (PFC, VTA, and $\mathrm{NuAc}$ ) were microdissected from each experimental animal (Figure 1). The PFC dissections were limited to laminae II-VI of the cortex on the medial bank of the frontal lobe at the level of the tenia tecta and contained primarily cingulate area 3 and the infralimbic cortex (Bregma, approximately 2.2-3.2 mm) (Figure $1 \mathrm{a}$ ). The NuAc dissections were taken from its shell region at the level of the genu of the corpus callosum (Bregma, approximately 0.7-1.6 mm) (Figure 1b). The VTA dissection was bounded by fasciculus retroflexus medially, the mammillary peduncle ventrally, the substantia nigra pars compacta and medial terminal nucleus of the accessory optic tract laterally, and the medial lemniscus dorsolaterally (Bregma, approximately -5.2 to $-5.3 \mathrm{~mm}$ ) (Figure 1c). Although this dissection does not contain the entire VTA, it is highly reproducible and includes the region previously shown to express both tyrosine hydroxylase and $5-\mathrm{HT}_{2 \mathrm{C}} \mathrm{R}$ mRNAs (Eberle-Wang et al, 1997). Care was taken to exclude any portion of the substantia nigra from the dissections.

Laser capture microdissection. On the day of microdissection, PEN slides at the anatomical level desired for dissection were identified by reference to nearly adjacent thionin-stained reference sections. The identified PEN slides were removed from the freezer, immediately fixed in $100 \%$ ethanol for $1 \mathrm{~min}$, and then rehydrated in a graded series of ethanol/water (95, 75, and 50\%; each $1 \mathrm{~min}$ ). Sections were then stained for $\sim 20 \mathrm{~s}$ in $1 \%$ thionin in $0.05 \mathrm{M} \mathrm{NaCH}{ }_{3} \mathrm{COO}$ buffer, $\mathrm{pH} 4.5$, dehydrated $(50,75$, 95 , and $100 \%$ ethanol, $1 \mathrm{~min}$ each), dried for $1 \mathrm{~min}$, and 
a

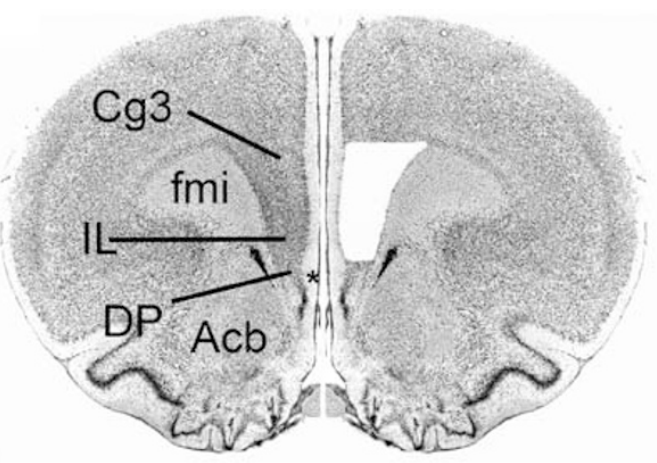

b

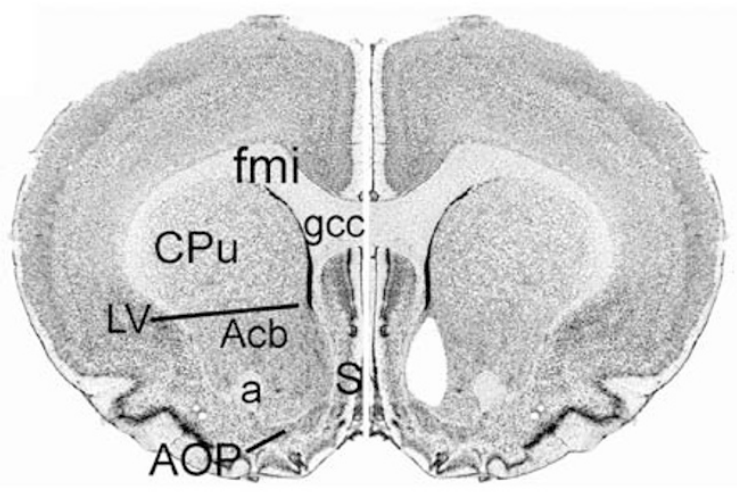

C

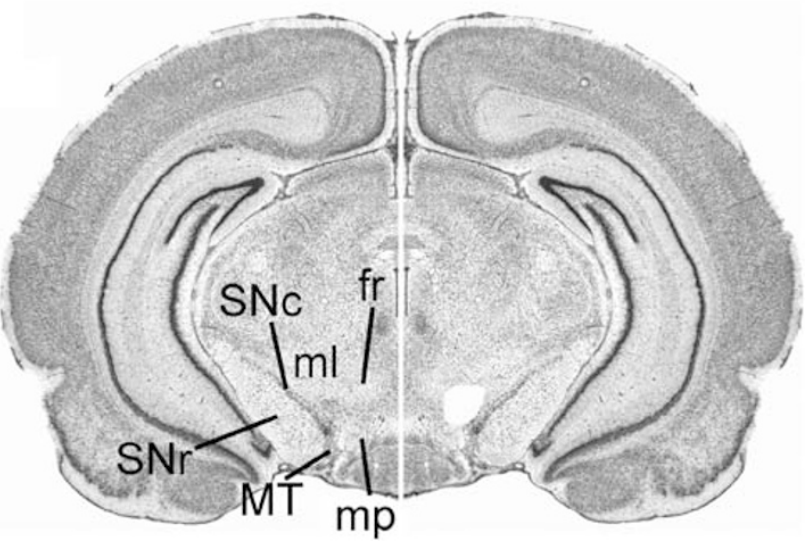

Figure I Illustration of dissections. Twenty-micron-thick thionin-stained sections before and after the dissection of regions of interest. For photography, tissue was covered with 100\% alcohol and temporarily coverslipped. Only one hemisphere is shown before dissection and the mirror image of that hemisphere is shown after dissection. (a) Level of PFC dissection. PFC dissections contained primarily Cg3 and IL. (b) Level of NuAc dissection. NuAc dissections were taken from its shell region at the level of gcc. (c) Level of VTA dissection. VTA was dissected only at levels where the fr could be seen. a, anterior commissure, Acb, nucleus accumbens; AOP, accessory olfactory nucleus posterior; Cg3, cingulate cortex area 3; DP, dorsal peduncular cortex; IL, infralimbic cortex; fmi, forceps minor corpus callosum; fr, fasciculus retroflexus; gcc, genu corpus callosum; LV, lateral ventricle; $\mathrm{ml}$, medial lemniscus; mp, mammillary peduncle; MT, medial terminal nucleus accessory optic tract; $\mathrm{S}$, septal area; SNc, substantia nigra pars compacta; SNr, substantia nigra pars reticulata.

immediately used for microdissection. All solutions were prepared with diethylpyrocarbonate-treated water. The individual regions were dissected by laser capture microdissection using Leica AS LMD (Leica Microsystems Inc.). The amount of dissected tissue varied for different regions because of the differences in their sizes. All delineations and dissections were performed blindly relative to the behavioral phenotypes of the animals.

\section{RNA Extraction and cDNA Synthesis}

Total RNA was extracted and treated with DNAse using the PicoPure RNA isolation Kit (Molecular Devices, Sunnyvale, CA). RNA quality and concentration were evaluated using BioAnalyzer (Agilent Technologies, Santa Clara, CA). All but two RNA preparations (one from the VTA and one from the NuAc) yielded high-quality RNAs (mean \pm SD of the RNA integrity numbers were $7.52 \pm 0.62$ ), and only those high-quality preparations were employed in the studies. cDNA was synthesized by reverse transcriptase (RT) reaction using iScript kit (BioRad, Hercules, CA). As RNA concentrations varied between the different regions, different amounts of isolated RNA were used for RT reactions in each region: $400 \mathrm{ng}$ (PFC), $100 \mathrm{ng}$ (VTA), and $250 \mathrm{ng}$ $(\mathrm{NuAc})$. For a given region, equal amounts of RNA were used for each animal.

\section{RNA Editing Analysis}

Amplification of the $5-H_{2 C} R$ region of editing. To minimize the influence of erroneous amplification in a single PCR that could alter the proportions of differently edited mRNA variants, three independent PCRs were performed for each animal and each region using a forward-ATCATGGCAGTAAGCATGG/reverse-ATCTTCAT GATGGCCTTAGTCCG primer pair and a touch-down cycling program as described earlier (Dracheva et al, 2003). As the reverse primer was designed within the area that is deleted in the truncated $5-\mathrm{HT}_{2 \mathrm{C}} \mathrm{R}$ mRNA splice variant (5- $\mathrm{HT}_{2 \mathrm{C}} \mathrm{Rsp} 1$; see below), only the full-length $5-\mathrm{HT}_{2 \mathrm{C}} \mathrm{R}$ (5- $\left.\mathrm{HT}_{2 \mathrm{C}} \mathrm{Rsp} 2\right) \mathrm{cDNA}$ was amplified in this PCR (Canton et al, 1996; Dracheva et al, 2003; Dracheva et al, 2008b).

Cloning and sequencing. PCR products of the three independent reactions generated for each animal and each brain region were combined and resolved by agarose gel electrophoresis. A single DNA product of $\sim 300 \mathrm{bp}$ was detected for each combined reaction. The amplicon of this size (302 bp) was expected from the full-length $5-\mathrm{HT}_{2 \mathrm{C}} \mathrm{R}$ cDNA. The DNA product was gel-purified using a MinElute Gel Extraction Kit (Qiagen, Valencia, CA), and subcloned into a pCR4-TOPO vector (Invitrogen, Carlsbad, CA). The recombinant plasmids were transformed into bacteria. From each bacterial transformation, which resulted in at least 300 clones expressing the recombinant plasmid DNA, 48 were picked randomly. Plasmid DNA was isolated, and the inserts of these plasmids were sequenced. The plasmid DNA insert from a single bacterial colony represented the edited region of an individual $5-\mathrm{HT}_{2 \mathrm{C}} \mathrm{R}$ mRNA transcript.

\section{Real-Time Quantitative PCR}

mRNA expression was measured by real-time quantitative PCR (qPCR) using an ABI Prism 7900 Sequence Detector and gene-specific TaqMan FAM/MGB assays (Applied Biosystems, Foster City, CA) as described earlier (Dracheva et al, 2008a). Pre-developed TaqMan FAM/MGB assays 
(Applied Biosystems) were employed for the endogenous control genes ( $\beta$-2 microglobulin $(B 2 M)$, Rn00560865_m1; peptidylprolyl isomerase A (PPIA), Rn00690933_m1; glyceraldehyde-3-phosphate dehydrogenase (GAPDH), Rn999 99916_s1; and $\beta$-actin (BACT), Rn00667869_m1) amplification. Similarly, a pre-developed assay was used for ADAR1 $(A D A R)$ (Rn00508006_m1) amplification, as only one splice variant is reported for this gene in rats (National Center for Biological Information (NCBI) accession number, NM_031006).

Four different splice variants of ADAR2 (ADARB1) are reported by the NCBI (see Results). As two ADAR2 alternative splice sites are situated $1400 \mathrm{bp}$ apart from each other, it was not feasible to design GPCR assays that would distinguish between all four individual transcript variants. Therefore, two assays were employed which distinguished between the transcripts that encode the functional protein (denoted as ADAR2f) and the non-functional (truncated) protein (denoted as ADAR2nonf). A pre-developed TaqMan assay (Rn00681060_m1) was used to detect ADAR2f transcript variants. This qPCR assay amplified only transcript variants 1 and 2 (NM_012894 and NM_001111055). A custom TaqMan assay was designed to detect ADAR2nonf variants. In this assay, the forward PCR primer was situated in the region of extra $47 \mathrm{bp}$ that is added to the ADAR2-coding region as a result of autoediting (see Results); therefore, only transcript variants 3 and 4 (NM_001111056 and NM_001111057) were amplified (ADAR2nonf assay: F-CTTTCTGGGCACCACAGGTT; R-GT TGTCCAGATTGCGGTTTTC; Probe-FAM-AGCAGCACTGA TGTTAA-MGB).

Two different custom TaqMan assays were designed to distinguish between two $5-\mathrm{HT}_{2 \mathrm{C}} \mathrm{R}$ splice variants (5- $\mathrm{HT}_{2 \mathrm{C}} \mathrm{Rsp} 1$ and $\left.5-\mathrm{HT}_{2 \mathrm{C}} \mathrm{Rsp} 2\right)$ that had been detected in the brain (see Results) (Dracheva et al, 2003; Flomen et al, 2004). In the $5-\mathrm{HT}_{2 \mathrm{C}} \mathrm{Rsp} 2$ assay, the probe and primers were situated inside the 95-bp region that is present in $5-\mathrm{HT}_{2 \mathrm{C}} \mathrm{Rsp} 2$, but is deleted in $5-\mathrm{HT}_{2 \mathrm{C}} \mathrm{Rsp} 1$; therefore, only 5- $\mathrm{HT}_{2 \mathrm{C}}$ Rsp 2 was amplified (5- $\mathrm{HT}_{2 \mathrm{C}} \mathrm{Rsp} 2$ assay: F-TGA GCATAGCCGGTTCAATTC; R-GCCCAAACGATGGCAAT CT; Probe-6FAM-CGGACTAAGGCCATCAT-MGB). In the $5-\mathrm{HT}_{2 \mathrm{C}} \mathrm{Rsp} 1$ assay, the forward PCR primer was designed to span the $s p 1$ site; therefore, only $5-\mathrm{HT}_{2 \mathrm{C}} \mathrm{Rsp} 1$ was amplified (5-HT ${ }_{2 \mathrm{C}}$ Rsp1 assay: F-CGCTGGACCGGAGTTTCA; R-ATTC ACGAACACTTTGCTTTCG; Probe-FAM-CCTATCCCTGT GATTGGA-MGB).

To account for the differences in the input material among the samples, the expression levels of $5-\mathrm{HT}_{2 \mathrm{C}} \mathrm{R}$, ADARI, and ADAR2 were normalized to the expression levels of the four above-mentioned endogenous controls (B2M, PPIA, GAPDH, and BACT) (Vandesompele et al, 2002). First, the relative expression levels of all transcripts were determined using Relative Standard Curve Method (RSCM; see Guide to Performing Relative Quantitation of Gene Expression Using Real-Time Quantitative PCR, Applied Biosystems), which provides accurate quantitative results by accounting for differences in the efficiencies between the target and the endogenous control(s) amplifications (Peirson et al, 2003). The standard curves were generated by the association between threshold cycle $\left(C_{\mathrm{t}}\right)$ values and different quantities of a 'calibrator' $\mathrm{CDNA}$, which was prepared by mixing small quantities of all experimental samples. Using the linear equations of the standard curves, the relative amounts of the target transcripts (ADAR1, ADAR2f, ADAR2nonf, 5- $\mathrm{HT}_{2 \mathrm{C}} \mathrm{Rsp} 1$, and 5- $\mathrm{HT}_{2 \mathrm{C}} \mathrm{Rsp} 2$ ) and the endogenous control transcripts were calculated in each sample. Then, the relative expression level of each target transcript was computed as the ratio between the amount of the target transcript and the geometric mean of the amounts of the four endogenous controls. The ADAR2f/ADAR1 ratio was calculated as the proportion between the relative expressions of ADAR2f and ADAR1.

\section{Statistical Analysis}

Editing data. The editing parameters obtained in the study were editing efficiencies at each of the five sites, the frequency of each detected $5-\mathrm{HT}_{2 \mathrm{C}} \mathrm{R}$ mRNA variant, and the frequency of each predicted $5-\mathrm{HT}_{2 \mathrm{C}} \mathrm{R}$ protein isoform. The data were analyzed using mixed-effects binomial regression (Hedeker and Gibbons, 1996) separately for each region as a function of phenotype (HRs or LRs). Editing efficiency was previously observed to exhibit a strong interdependence among all five sites (Carmel, L. et al, unpublished observation). Editing efficiencies at A, B, C, and $\mathrm{D}$ editing sites were, therefore, handled as repeated measures using a random effect. Owing to the low editing efficiency (less than 5\% in the PFC and VTA), the E site was not included in the analysis. The differences between regions were considered with HRs and LRs combined. The differences in editing efficiencies were confirmed using Tukey's Studentized Range Test.

Gene expression data. The relative mRNA expression of ADAR1, ADAR2f, ADAR2nonf, 5- $\mathrm{HT}_{2 \mathrm{C}} \mathrm{Rsp} 1$, and $5-\mathrm{HT}_{2 \mathrm{C}} \mathrm{Rsp} 2$ and the ADAR2f/ADAR1 ratio were compared among the three brain regions for HRs and LRs by repeated measures analysis of variance (ANOVA) for the 35 subjects with complete data (17 HRs and 18 LRs). The Huynh-Feldt adjustment of degrees of freedom was used to correct for violation of sphericity assumptions. In addition, the HRs and LRs were compared separately within each brain region by one-way ANOVA, and each pair of brain regions was compared by matched sample $t$-tests, including both HRs and LRs.

Correlation analysis. Correlations between the expression levels of ADARs and the editing efficiencies at all five editing sites, as well as correlations among ADARs expression levels, were examined within each region and across all regions. As a total of 28 correlations were examined, a criterion for significance was set at $p<0.05 / 28=0.0012$.

\section{RESULTS}

\section{Evaluation of Behavioral Phenotypes}

The weight of rats varied between 250 and $320 \mathrm{~g}$ at the time of behavioral testing and there were significant differences in weights between the two sets of animals (mean \pm SEM; set 1 , $272 \pm 1.9 \mathrm{~g}$; set $2,284 \pm 2.7 \mathrm{~g} ; p<0.001$ ). Therefore, although no correlation was observed between the individual locomotor score and the weight of the animals (set 1: $r=-0.088$, $p=0.57$; set $2: r=0.190, p=0.19)$, weight was used as a 
Table I Efficiency of Editing at the Five Editing Sites (A, B, E, C, and D) of the 5-HT 2 C R mRNA in Rat PFC, NuAc, and VTA

\begin{tabular}{|c|c|c|c|c|c|c|c|c|c|}
\hline \multirow{2}{*}{ Editing sites } & \multicolumn{3}{|c|}{ PFC (\%) } & \multicolumn{3}{|c|}{ VTA (\%) } & \multicolumn{3}{|c|}{ NuAc (\%) } \\
\hline & $\begin{array}{l}\text { All rats } \\
(N=38)\end{array}$ & $\begin{array}{c}\text { LRs } \\
(N=19)\end{array}$ & $\begin{array}{c}\text { HRs } \\
(N=19)\end{array}$ & $\begin{array}{l}\text { All rats } \\
(N=37)\end{array}$ & $\begin{array}{c}\text { LRs } \\
(N=18)\end{array}$ & $\begin{array}{c}\text { HRs } \\
(N=19)\end{array}$ & $\begin{array}{l}\text { All rats } \\
(N=37)\end{array}$ & $\begin{array}{c}\text { LRs } \\
(N=19)\end{array}$ & $\begin{array}{c}\text { HRs } \\
(N=18)\end{array}$ \\
\hline A & $94.6 \pm 0.6$ & $93.1 \pm 0.8$ & $96.1 \pm 0.7$ & $96.5 \pm 0.4$ & $96.6 \pm 0.6$ & $96.4 \pm 0.7$ & $93.9 \pm 0.6$ & $93.9 \pm 0.9$ & $93.9 \pm 0.7$ \\
\hline B & $88.2 \pm 0.9$ & $86.9 \pm 1.0$ & $89.6 \pm 1.4$ & $88.9 \pm 0.8$ & $89.5 \pm 0.9$ & $88.4 \pm 1.5$ & $88.4 \pm 0.9$ & $86.6 \pm 1.5$ & $90.3 \pm 0.8$ \\
\hline$E$ & $3.9 \pm 0.4$ & $4.4 \pm 0.8$ & $3.5 \pm 0.5$ & $3.5 \pm 0.4$ & $4.5 \pm 0.6$ & $2.5 \pm 0.5$ & $5.4 \pm 0.6$ & $5.6 \pm 0.9$ & $5.1 \pm 0.7$ \\
\hline$D$ & $62.3 \pm 1.3$ & $60.8 \pm 1.5$ & $63.8 \pm 2.2$ & $67.1 \pm 1.2$ & $68.1 \pm 1.9$ & $66.3 \pm 1.5$ & $84.0 \pm 1.1$ & $83.0 \pm 1.8$ & $85.0 \pm 1.3$ \\
\hline
\end{tabular}

Shown in bold font: editing efficiency was significantly higher in HRs compared to that in LRs ( $p=0.015)$.

covariate in the analysis of locomotor scores. Analysis of covariance showed no differences between locomotor activity scores recorded for each daily group (10 groups, 10/12 animals per group; $\mathrm{F}(1,9)=0.812, p=0.62$ ). Still, because two sets of rats were processed separately and analyzed at different times (4 weeks apart), the individual locomotor score for each rat was normalized by dividing it by the average of the activity counts for that set of animals. These adjusted scores were used for statistical analyses.

As in other studies (Marinelli, 2005), the normalized locomotor activity scores were approximately normally distributed (Kolmogorov-Smirnov $z=0.78, p=0.58$ ). Highand low-responder phenotypes were defined by the upper and lower ends of this distribution (approximately $1 \mathrm{SD}$ above and 1 SD below the mean, respectively): from the 104 animals assessed, 19 with the highest scores were designated as HRs and 19 with the lowest scores as LRs.

\section{Analysis of RNA Editing}

Overall analysis. Nucleotide sequence analysis was performed for a total of $51365-\mathrm{HT}_{2 \mathrm{C}} \mathrm{R}$ cDNA clones that were generated from the RNA specimens extracted from three different brain regions (PFC, NuAc shell, and VTA) of 38 rats (19 LRs and $19 \mathrm{HRs).} \mathrm{Owing} \mathrm{to} \mathrm{low} \mathrm{concentration,} \mathrm{two}$ RNA specimens (one from the VTA and one from the $\mathrm{NuAc}$ ) were not analyzed. On average, 45.7 clones (range, 43-48) were analyzed for each animal in each region, which provided for a reliable analysis of editing as was determined by Sodhi et al (2005). The value of each RNA editing parameter (editing efficiency at each site, observed mRNA variants, and predicted protein isoforms) was calculated as the proportion of the number of clones analyzed per specimen. The mean values of these proportions (termed 'frequencies' for the RNA variants and protein isoforms, and 'efficiencies' for the levels of editing at each editing site) within each of the study groups (the entire group, LRs, and HRs) and within each brain region (PFC, NuAc shell, and VTA) are shown in Tables 1-3.

Twenty-seven of the 32 possible $5-\mathrm{HT}_{2 \mathrm{C}} \mathrm{R}$ RNA variants were detected in the entire group among different regions ( $B C, B E, B E C, B E D$, and $B E C D$ were not detected). Only four of the detected variants, which contained editing combinations $A B D, A B C D, A B$, and $A B C$, were observed at $\sim 5 \%$ or greater frequency in at least one of the study groups (Table 2). Taken together, these four variants constituted majority of the $5-\mathrm{HT}_{2 \mathrm{C}} \mathrm{R}$ transcripts $(84.4 \%$ in the $\mathrm{PFC}$,
$85.4 \%$ in the VTA, and $83.9 \%$ in the NuAc shell). Of the 24 predicted $5-\mathrm{HT}_{2 \mathrm{C}} \mathrm{R}$ protein isoforms, RNA was detected for 19 (MDI, MDV, MGI, MSI, and MGV were not detected); only four of the predicted isoforms (VNV, VNI, VSV, and VSI) had a frequency of $5 \%$ or greater (Table 3). Taken together, these four predicted isoforms represented approximately $90 \%$ of the $5-\mathrm{HT}_{2 \mathrm{C}} \mathrm{R}$ protein $(90.8 \%$ in the $\mathrm{PFC}$, 93.4\% in the VTA, and $89.1 \%$ in the NuAc shell).

Comparison between HRs and LRs. The editing efficiency was significantly higher in HRs compared with that in LRs in the PFC $(z=2.44, p=0.0145)$; no differences were detected in the VTA and NuAc shell (Table 1). Similarly, the frequency of $A B C D$ was significantly higher for HRs only in the PFC $(z=2.10, p=0.0352$; Figure 2a, Table 2). Consequently, the frequency of VSV (that is encoded by $A B C D$ ) was higher for HRs compared with that for LRs in the PFC $(z=2.15, p=0.0315$; Figure $2 b$, Table 3$)$. No differences between HRs and LRs were detected in the frequencies of $A B D, A B, A B C, \mathrm{VNV}, \mathrm{VNI}$, and VSI in any region (see Figure $2 \mathrm{a}$ and $\mathrm{b}$ for $A B D$ and VNV, respectively).

Comparison between the regions. The editing efficiency at the A, B, C, and D sites (analyzed as repeated measures) was significantly higher in the NuAc shell compared with the PFC and VTA ( $z$-values $>6.14, p$-values $<0.0001$; Figure $3 a)$. Tukey's Studentized Range Test showed that for site $C$, there was a significant increase of editing efficiency in the NuAc compared with the VTA (95\% CI: 0.0056, 0.0916). For site D, there was a significant increase of editing in the $\mathrm{NuAc}$ compared with the VTA (95\% CI: 0.1272, 0.2097), in the NuAc compared with the PFC (95\% CI: 0.1755, 0.2575), and in the VTA compared with the PFC (95\% CI: 0.0070, 0.0890).

The frequency of $A B D$ was significantly lower in the PFC compared with the $\mathrm{NuAc}$ shell $(z=3.28, p=0.001$; Figure $3 \mathrm{~b})$. The frequency of $A B C D$ was significantly higher in the NuAc shell compared with the PFC and VTA ( $z$-values $>7.17, p$-values $<0.0001$; Figure $3 b)$. The frequencies of $A B$ and $A B C$ were significantly lower in the NuAc shell compared with the PFC and VTA $(z$-values $>6.89$, $p$-values $<0.0001$; Figure $3 \mathrm{~b})$. The frequency of VNV was significantly lower in the PFC compared with the NuAc shell $(z=4.21, p<0.0001)$ and VTA $(z=2.49, p=0.013)$. The frequency of VSV was significantly higher in the NuAc shell compared with the PFC and VTA $(z$-values $>7.16$, $p$-values $<0.0001$; Figure $3 c$ ). The frequencies of VSI and VNI 
Table 2 Frequencies for the Observed 5-HT2CR mRNA Variants

\begin{tabular}{|c|c|c|c|c|c|c|c|c|c|c|}
\hline \multirow{2}{*}{ mRNA variant } & \multicolumn{4}{|c|}{ PFC (\%) } & \multicolumn{3}{|c|}{ VTA (\%) } & \multicolumn{3}{|c|}{ NuAc (\%) } \\
\hline & $\begin{array}{c}{ }^{\$} \text { Human PFC; NC } \\
(N=35)\end{array}$ & $\begin{array}{l}\text { All rats } \\
(N=38)\end{array}$ & $\begin{array}{c}\text { LRs } \\
(N=19)\end{array}$ & $\begin{array}{c}\text { HRs } \\
(N=19)\end{array}$ & $\begin{array}{l}\text { All rats } \\
(N=37)\end{array}$ & $\begin{array}{c}\text { LRs } \\
(N=18)\end{array}$ & $\begin{array}{c}\text { HRs } \\
(N=19)\end{array}$ & $\begin{array}{l}\text { All rats } \\
(N=37)\end{array}$ & $\begin{array}{c}\text { LRs } \\
(N=19)\end{array}$ & $\begin{array}{c}\text { HRs } \\
(N=18)\end{array}$ \\
\hline$A B D$ & $15.9 \pm 1.2$ & $39.7 \pm 1.5$ & $40.4 \pm 1.9$ & $39.1 \pm 2.3$ & $42.3 \pm 1.2$ & $43.0 \pm 1.7$ & $41.7 \pm 1.7$ & $45.4 \pm 1.2$ & $44.4 \pm 1.9$ & $46.4 \pm 1.4$ \\
\hline$A B C D$ & $19.2 \pm 1.2$ & $17.6 \pm 0.9$ & $* 15.7 \pm 1.2$ & $19.5 \pm 1.1$ & $18.1 \pm 1.0$ & $17.8 \pm 1.5$ & $18.4 \pm 1.4$ & $28.5 \pm 1.0$ & $27.9 \pm 1.8$ & $29.2 \pm 1.1$ \\
\hline$A B$ & $2.7 \pm 0.6$ & $15.2 \pm 1.0$ & $15.1 \pm 1.5$ & $15.4 \pm 1.3$ & $14.3 \pm 1.0$ & $13.4 \pm 1.7$ & $15.2 \pm 1.1$ & $5.6 \pm 0.5$ & $5.6 \pm 0.7$ & $5.6 \pm 0.8$ \\
\hline$A B C$ & $2.9 \pm 0.5$ & $11.8 \pm 0.8$ & $11.5 \pm 1.1$ & $12.1 \pm 1.1$ & $10.6 \pm 0.8$ & $11.2 \pm 1.0$ & $10.1 \pm 1.2$ & $4.4 \pm 0.5$ & $3.8 \pm 0.7$ & $5.0 \pm 0.7$ \\
\hline$A$ & $6.6 \pm 0.7$ & $4.1 \pm 0.4$ & $4.2 \pm 0.6$ & $3.9 \pm 0.7$ & $4.2 \pm 0.5$ & $4.0 \pm 0.8$ & $4.3 \pm 0.8$ & $2.1 \pm 0.5$ & $2.9 \pm 0.8$ & $1.2 \pm 0.3$ \\
\hline NONE & $8.7 \pm 1.1$ & $2.6 \pm 0.4$ & $3.2 \pm 0.5$ & $2.0 \pm 0.6$ & $0.9 \pm 0.3$ & $0.6 \pm 0.2$ & $1.2 \pm 0.5$ & $1.9 \pm 0.3$ & $2.3 \pm 0.5$ & $1.5 \pm 0.5$ \\
\hline ABED & $1.9 \pm 0.4$ & $1.2 \pm 0.3$ & $1.5 \pm 0.4$ & $0.9 \pm 0.3$ & $0.8 \pm 0.2$ & $1.2 \pm 0.3$ & $0.5 \pm 0.3$ & $2.5 \pm 0.4$ & $2.6 \pm 0.7$ & $2.4 \pm 0.6$ \\
\hline$A C$ & $2.8 \pm 0.5$ & I. $1 \pm 0.3$ & I. $1 \pm 0.4$ & $1.0 \pm 0.4$ & $0.8 \pm 0.2$ & $0.5 \pm 0.2$ & $1.2 \pm 0.3$ & $0.3 \pm 0.1$ & $0.4 \pm 0.2$ & $0.2 \pm 0.2$ \\
\hline$A B E$ & $0.4 \pm 0.2$ & $1.0 \pm 0.3$ & $1.3 \pm 0.4$ & $0.8 \pm 0.3$ & $0.7 \pm 0.2$ & $0.6 \pm 0.2$ & $0.7 \pm 0.3$ & $0.3 \pm 0.1$ & $0.5 \pm 0.2$ & $0.1 \pm 0.1$ \\
\hline D & $3.8 \pm 0.6$ & $0.9 \pm 0.2$ & $1.0 \pm 0.3$ & $0.7 \pm 0.3$ & $0.9 \pm 0.3$ & $1.1 \pm 0.4$ & $0.7 \pm 0.3$ & $1.9 \pm 0.3$ & $1.8 \pm 0.6$ & $1.9 \pm 0.4$ \\
\hline$A D$ & $6.4 \pm 0.7$ & $0.8 \pm 0.2$ & $0.6 \pm 0.3$ & $1.0 \pm 0.4$ & $2.6 \pm 0.4$ & $2.2 \pm 0.5$ & $2.9 \pm 0.6$ & $2.4 \pm 0.4$ & $3.1 \pm 0.7$ & $1.7 \pm 0.4$ \\
\hline C & $2.1 \pm 0.3$ & $0.6 \pm 0.2$ & $0.9 \pm 0.3$ & $0.3 \pm 0.2$ & $0.5 \pm 0.2$ & $0.5 \pm 0.2$ & $0.5 \pm 0.2$ & $0.4 \pm 0.2$ & $0.5 \pm 0.2$ & $0.4 \pm 0.3$ \\
\hline$C D$ & $2.6 \pm 0.5$ & $0.6 \pm 0.2$ & $0.7 \pm 0.3$ & $0.5 \pm 0.3$ & $0.2 \pm 0.1$ & $0.2 \pm 0.2$ & $0.1 \pm 0.1$ & $1.1 \pm 0.2$ & $0.9 \pm 0.3$ & $1.3 \pm 0.4$ \\
\hline$A B E C D$ & $3.9 \pm 0.7$ & $0.6 \pm 0.2$ & $0.2 \pm 0.2$ & $0.9 \pm 0.3$ & $0.9 \pm 0.2$ & $1.2 \pm 0.3$ & $0.6 \pm 0.2$ & $1.1 \pm 0.3$ & $1.3 \pm 0.4$ & $0.9 \pm 0.4$ \\
\hline$A B E C$ & $1.0 \pm 0.3$ & $0.5 \pm 0.2$ & $0.7 \pm 0.3$ & $0.3 \pm 0.2$ & $0.4 \pm 0.1$ & $0.6 \pm 0.2$ & $0.2 \pm 0.2$ & $0.4 \pm 0.2$ & $0.3 \pm 0.2$ & $0.5 \pm 0.3$ \\
\hline$A C D$ & $5.0 \pm 0.7$ & $0.4 \pm 0.1$ & $0.4 \pm 0.2$ & $0.5 \pm 0.2$ & $0.4 \pm 0.1$ & $0.5 \pm 0.2$ & $0.2 \pm 0.2$ & $0.4 \pm 0.1$ & $0.6 \pm 0.2$ & $0.2 \pm 0.2$ \\
\hline$B D$ & $0.7 \pm 0.3$ & $0.4 \pm 0.2$ & $0.5 \pm 0.2$ & $0.3 \pm 0.3$ & $0.5 \pm 0.2$ & $0.2 \pm 0.2$ & $0.7 \pm 0.2$ & $0.1 \pm 0.1$ & $0.0 \pm 0.0$ & $0.1 \pm 0.1$ \\
\hline$A E C$ & $3.5 \pm 0.5$ & $0.3 \pm 0.1$ & $0.5 \pm 0.2$ & $0.1 \pm 0.1$ & $0.1 \pm 0.1$ & $0.0 \pm 0.0$ & $0.2 \pm 0.2$ & $0.3 \pm 0.1$ & $0.3 \pm 0.2$ & $0.2 \pm 0.2$ \\
\hline$A E$ & $1.1 \pm 0.3$ & $0.2 \pm 0.1$ & $0.2 \pm 0.2$ & $0.1 \pm 0.1$ & $0.1 \pm 0.1$ & $0.2 \pm 0.2$ & $0.0 \pm 0.0$ & $0.1 \pm 0.1$ & $0.1 \pm 0.1$ & $0.0 \pm 0.0$ \\
\hline B & $1.7 \pm 0.4$ & $0.2 \pm 0.1$ & $0.3 \pm 0.2$ & $0.0 \pm 0.0$ & $0.1 \pm 0.1$ & $0.1 \pm 0.1$ & $0.0 \pm 0.0$ & $0.1 \pm 0.1$ & $0.1 \pm 0.1$ & $0.0 \pm 0.0$ \\
\hline$E D$ & $0.2 \pm 0.1$ & $0.1 \pm 0.1$ & $0.0 \pm 0.0$ & $0.1 \pm 0.1$ & $0.2 \pm 0.1$ & $0.4 \pm 0.2$ & $0.1 \pm 0.1$ & $0.3 \pm 0.2$ & $0.1 \pm 0.1$ & $0.5 \pm 0.3$ \\
\hline$A E D$ & $0.8 \pm 0.2$ & $0.1 \pm 0.1$ & $0.0 \pm 0.0$ & $0.1 \pm 0.1$ & $0.1 \pm 0.1$ & $0.1 \pm 0.1$ & $0.0 \pm 0.0$ & $0.1 \pm 0.1$ & $0.1 \pm 0.1$ & $0.0 \pm 0.0$ \\
\hline$A E C D$ & $4.3 \pm 0.6$ & $0.0 \pm 0.0$ & $0.0 \pm 0.0$ & $0.0 \pm 0.0$ & $0.1 \pm 0.1$ & $0.0 \pm 0.0$ & $0.1 \pm 0.1$ & $0.1 \pm 0.1$ & $0.0 \pm 0.0$ & $0.1 \pm 0.1$ \\
\hline$B C D$ & $0.2 \pm 0.1$ & $0.0 \pm 0.0$ & $0.0 \pm 0.0$ & $0.0 \pm 0.0$ & $0.2 \pm 0.1$ & $0.1 \pm 0.1$ & $0.2 \pm 0.2$ & $0.1 \pm 0.1$ & $0.1 \pm 0.1$ & $0.0 \pm 0.0$ \\
\hline E & $0.6 \pm 0.2$ & $0.0 \pm 0.0$ & $0.0 \pm 0.0$ & $0.0 \pm 0.0$ & $0.1 \pm 0.1$ & $0.1 \pm 0.1$ & $0.0 \pm 0.0$ & $0.2 \pm 0.1$ & $0.1 \pm 0.1$ & $0.2 \pm 0.2$ \\
\hline$E C$ & $0.5 \pm 0.2$ & $0.0 \pm 0.0$ & $0.0 \pm 0.0$ & $0.0 \pm 0.0$ & $0.1 \pm 0.1$ & $0.0 \pm 0.0$ & $0.1 \pm 0.1$ & $0.0 \pm 0.0$ & $0.0 \pm 0.0$ & $0.0 \pm 0.0$ \\
\hline$E C D$ & $0.1 \pm 0.1$ & $0.0 \pm 0.0$ & $0.0 \pm 0.0$ & $0.0 \pm 0.0$ & $0.0 \pm 0.0$ & $0.0 \pm 0.0$ & $0.0 \pm 0.0$ & $0.1 \pm 0.1$ & $0.1 \pm 0.1$ & $0.1 \pm 0.1$ \\
\hline
\end{tabular}

The data represent means + SEM of the frequencies in each study group. Only the mRNA variants that were detected at $\sim 5 \%$ or greater frequency in at least one study group (highlighted) were analyzed. $\$$ Editing frequencies in the human PFC of the psychiatrically normal control subjects (NC; $N=35$ ) are adopted from Dracheva et al (2008c). Shown in bold font: editing frequency of $A B C D$ was significantly higher in HRs compared with that in LRs in PFC ( $P=0.035)$. 
Table 3 Frequencies for the Predicted 5- $\mathrm{HT}_{2} \mathrm{C}$ Isoforms

\begin{tabular}{|c|c|c|c|c|c|c|c|c|c|c|}
\hline \multirow{2}{*}{ Isoform } & \multicolumn{4}{|c|}{ PFC (\%) } & \multicolumn{3}{|c|}{ VTA (\%) } & \multicolumn{3}{|c|}{ NuAc (\%) } \\
\hline & $\begin{array}{c}{ }^{\$} \text { Human PFC; NC } \\
(N=35)\end{array}$ & $\begin{array}{l}\text { All rats } \\
(N=38)\end{array}$ & $\begin{array}{c}\text { LRs } \\
(N=19)\end{array}$ & $\begin{array}{c}\text { HRs } \\
(\mathrm{N}=19)\end{array}$ & $\begin{array}{l}\text { All rats } \\
(N=37)\end{array}$ & $\begin{array}{c}\text { LRs } \\
(N=18)\end{array}$ & $\begin{array}{c}\text { HRs } \\
(N=19)\end{array}$ & $\begin{array}{l}\text { All rats } \\
(N=37)\end{array}$ & $\begin{array}{c}\text { LRs } \\
(N=19)\end{array}$ & $\begin{array}{c}\text { HRs } \\
(N=18)\end{array}$ \\
\hline$\overline{\text { VNV }}$ & $22.3 \pm 1.28$ & $40.6 \pm 1.4$ & $41.0 \pm 1.9$ & $40.2 \pm 2.1$ & $44.9 \pm 1.2$ & $45.2 \pm 1.7$ & $44.6 \pm 1.9$ & $47.8 \pm 1.2$ & $47.4 \pm 2.0$ & $48.1 \pm 1.4$ \\
\hline VNI & $9.4 \pm 0.80$ & $19.3 \pm 1.2$ & $19.3 \pm 1.7$ & $19.4 \pm 1.7$ & $18.5 \pm 1.1$ & $17.5 \pm 1.7$ & $19.5 \pm 1.3$ & $7.7 \pm 0.7$ & $8.6 \pm 1.1$ & $6.8 \pm 0.8$ \\
\hline VSV & $24.3 \pm 1.10$ & $18.0 \pm 0.9$ & $* 16.0 \pm 1.2$ & $20.0 \pm 1.1$ & $18.5 \pm 1.0$ & $18.3 \pm 1.6$ & $18.7 \pm 1.5$ & $29.0 \pm 1.0$ & $28.5 \pm 1.8$ & $29.5 \pm 1.1$ \\
\hline VSI & $5.8 \pm 0.62$ & $12.9 \pm 0.9$ & $12.7 \pm 1.2$ & $13.1 \pm 1.3$ & $11.5 \pm 0.8$ & $11.7 \pm 1.0$ & $11.3 \pm 1.3$ & $4.7 \pm 0.5$ & $4.1 \pm 0.7$ & $5.2 \pm 0.7$ \\
\hline $\mathrm{INI}$ & $8.7 \pm 1.08$ & $2.6 \pm 0.4$ & $3.2 \pm 0.5$ & $2.0 \pm 0.6$ & $0.9 \pm 0.3$ & $0.6 \pm 0.2$ & $1.2 \pm 0.5$ & $1.9 \pm 0.3$ & $2.3 \pm 0.5$ & $1.5 \pm 0.5$ \\
\hline VDV & $2.7 \pm 0.48$ & $1.3 \pm 0.3$ & $1.5 \pm 0.4$ & $1.0 \pm 0.4$ & $0.9 \pm 0.2$ & $1.3 \pm 0.3$ & $0.5 \pm 0.3$ & $2.6 \pm 0.4$ & $2.7 \pm 0.7$ & $2.4 \pm 0.6$ \\
\hline VDI & $1.4 \pm 0.37$ & $1.2 \pm 0.3$ & $1.5 \pm 0.4$ & $0.9 \pm 0.3$ & $0.8 \pm 0.2$ & $0.8 \pm 0.3$ & $0.7 \pm 0.3$ & $0.4 \pm 0.2$ & $0.6 \pm 0.3$ & $0.1 \pm 0.1$ \\
\hline INV & $3.8 \pm 0.59$ & $0.9 \pm 0.2$ & $1.0 \pm 0.3$ & $0.7 \pm 0.3$ & $0.9 \pm 0.3$ & $1.1 \pm 0.4$ & $0.7 \pm 0.3$ & $1.9 \pm 0.3$ & $1.8 \pm 0.6$ & $1.9 \pm 0.4$ \\
\hline VGI & $4.5 \pm 0.61$ & $0.8 \pm 0.3$ & I. I \pm 0.4 & $0.5 \pm 0.3$ & $0.5 \pm 0.2$ & $0.6 \pm 0.2$ & $0.5 \pm 0.2$ & $0.7 \pm 0.2$ & $0.7 \pm 0.2$ & $0.7 \pm 0.3$ \\
\hline$|S|$ & $2.1 \pm 0.32$ & $0.6 \pm 0.2$ & $0.9 \pm 0.3$ & $0.3 \pm 0.2$ & $0.5 \pm 0.1$ & $0.5 \pm 0.2$ & $0.5 \pm 0.2$ & $0.4 \pm 0.2$ & $0.5 \pm 0.2$ & $0.4 \pm 0.3$ \\
\hline ISV & $2.6 \pm 0.46$ & $0.6 \pm 0.2$ & $0.7 \pm 0.3$ & $0.5 \pm 0.3$ & $0.2 \pm 0.1$ & $0.2 \pm 0.2$ & $0.1 \pm 0.1$ & I. $1 \pm 0.2$ & $0.9 \pm 0.3$ & $1.3 \pm 0.4$ \\
\hline VGV & $8.2 \pm 0.88$ & $0.6 \pm 0.2$ & $0.2 \pm 0.2$ & $0.9 \pm 0.3$ & $0.9 \pm 0.2$ & $1.2 \pm 0.3$ & $0.7 \pm 0.2$ & $1.2 \pm 0.3$ & $1.3 \pm 0.4$ & $1.1 \pm 0.4$ \\
\hline MNV & $0.7 \pm 0.29$ & $0.4 \pm 0.2$ & $0.5 \pm 0.2$ & $0.3 \pm 0.3$ & $0.5 \pm 0.1$ & $0.2 \pm 0.2$ & $0.7 \pm 0.2$ & $0.1 \pm 0.1$ & $0.0 \pm 0.0$ & $0.1 \pm 0.1$ \\
\hline $\mathrm{MNI}$ & $1.7 \pm 0.40$ & $0.2 \pm 0.1$ & $0.3 \pm 0.2$ & $0.0 \pm 0.0$ & $0.1 \pm 0.1$ & $0.1 \pm 0.1$ & $0.0 \pm 0.0$ & $0.1 \pm 0.1$ & $0.1 \pm 0.1$ & $0.0 \pm 0.0$ \\
\hline IDV & $0.2 \pm 0.14$ & $0.1 \pm 0.1$ & $0.0 \pm 0.0$ & $0.1 \pm 0.1$ & $0.2 \pm 0.1$ & $0.4 \pm 0.2$ & $0.1 \pm 0.1$ & $0.3 \pm 0.2$ & $0.1 \pm 0.1$ & $0.5 \pm 0.3$ \\
\hline$|\mathrm{D}|$ & $0.6 \pm 0.21$ & $0.0 \pm 0.0$ & $0.0 \pm 0.0$ & $0.0 \pm 0.0$ & $0.1 \pm 0.1$ & $0.1 \pm 0.1$ & $0.0 \pm 0.0$ & $0.2 \pm 0.1$ & $0.1 \pm 0.1$ & $0.2 \pm 0.2$ \\
\hline$|G|$ & $0.5 \pm 0.18$ & $0.0 \pm 0.0$ & $0.0 \pm 0.0$ & $0.0 \pm 0.0$ & $0.1 \pm 0.1$ & $0.0 \pm 0.0$ & $0.1 \pm 0.1$ & $0.0 \pm 0.0$ & $0.0 \pm 0.0$ & $0.0 \pm 0.0$ \\
\hline IGV & $0.1 \pm 0.06$ & $0.0 \pm 0.0$ & $0.0 \pm 0.0$ & $0.0 \pm 0.0$ & $0.0 \pm 0.0$ & $0.0 \pm 0.0$ & $0.0 \pm 0.0$ & $0.1 \pm 0.1$ & $0.1 \pm 0.1$ & $0.1 \pm 0.1$ \\
\hline MSV & $0.2 \pm 0.11$ & $0.0 \pm 0.0$ & $0.0 \pm 0.0$ & $0.0 \pm 0.0$ & $0.2 \pm 0.1$ & $0.1 \pm 0.1$ & $0.2 \pm 0.2$ & $0.1 \pm 0.1$ & $0.1 \pm 0.1$ & $0.0 \pm 0.0$ \\
\hline
\end{tabular}

The data represent means \pm SEM of the frequencies in each study group. Only the isoforms that had $5 \%$ or greater frequency in at least one study group (highlighted) were analyzed. "Editing frequencies in the human in the PFC (* 

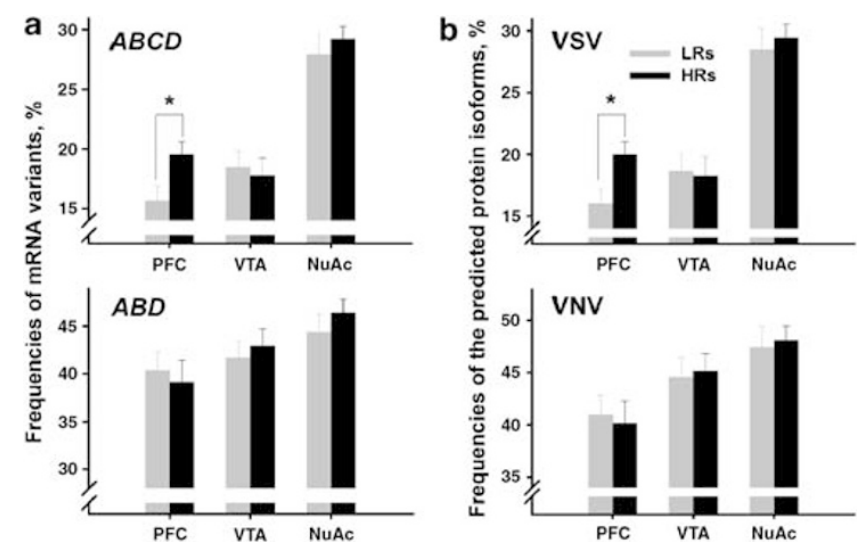

Figure 2 Region-specific frequencies of the two most prevalent 5- $\mathrm{HT}_{2} \mathrm{R}$ mRNA variants ( $A B D$ and $A B C D$, panel a) and the two most prevalent $5-H_{2} T_{2} R$ protein isoforms (VNV and VSV, panel $b$ ) in HRs and LRs. Shown are means \pm SEM. ABCD and VSV were significantly increased in the PFC of HRs compared with that of LRs $(* p<0.05)$.

were significantly lower in the NuAc shell compared with the PFC and VTA ( $z$-values $>7.23$, $p$-values $<0.0001$; Figure $3 c$ ).

\section{Analysis of 5-HT $2 \mathrm{C}$, ADAR1, and ADAR2 mRNA Expression}

In addition to a constitutive $5^{\prime}$ splice site, $s p 2,5-\mathrm{HT}_{2 \mathrm{C}} \mathrm{R}$ pre-mRNA undergoes alternative splicing between exons 5 and 6, with two alternative splice sites described-sp1 and sp3 (Canton et al, 1996; Flomen et al, 2004). Although the mRNA variant generated from splicing at $s p 2$ is translated into a functional receptor, both of the resulting alternative splice variants are translated into truncated proteins that are unlikely to retain adequate receptor function. The splicing at the $s p 3$ site was found to be extremely rare both in cell culture and in the brain (Dracheva et al, 2003; Flomen et al, 2004). Two custom TaqMan assays (see Methods) were employed in this study to detect each of the two $5-\mathrm{HT}_{2 \mathrm{C}} \mathrm{R}$ splice variants expressed in the brain$5-\mathrm{HT}_{2 \mathrm{C}} \mathrm{Rsp} 1$ and $5-\mathrm{HT}_{2 \mathrm{C}} \mathrm{Rsp} 2-$ that result from splicing at $s p 1$ and $s p 2$, respectively.

Four different splice variants of ADAR2 (ADARB1), which originate from constitutive and two alternative splicing events, are reported by the NCBI. The mammalian ADAR2 pre-mRNA transcript is edited by its own protein to produce an alternative intronal $3^{\prime}$-splice site. This splice site adds an extra 47 nucleotides to the ADAR2 mRNA coding region, creating a frame shift that results in a non-functional truncated protein (Rueter et al, 1999). In addition, ADAR2 pre-mRNA carries an alternative in-frame donor splice site in one of the internal coding exons, resulting in a shorter transcript that is missing a 10-aa segment. Transcript variant 1 (NM_012894) is the longest variant that does not undergo any alternative splicing and encodes a functional protein; transcript variant 2 (NM_001111055) uses an alternative in-frame donor splice site in the coding exon and encodes a functional protein that is 10-aa shorter than the first isoform; transcript variant 3 (NM_001111056) uses an alternative intronal splice site and encodes a non-functional truncated protein; transcript variant 4 (NM_001111057) uses both alternative
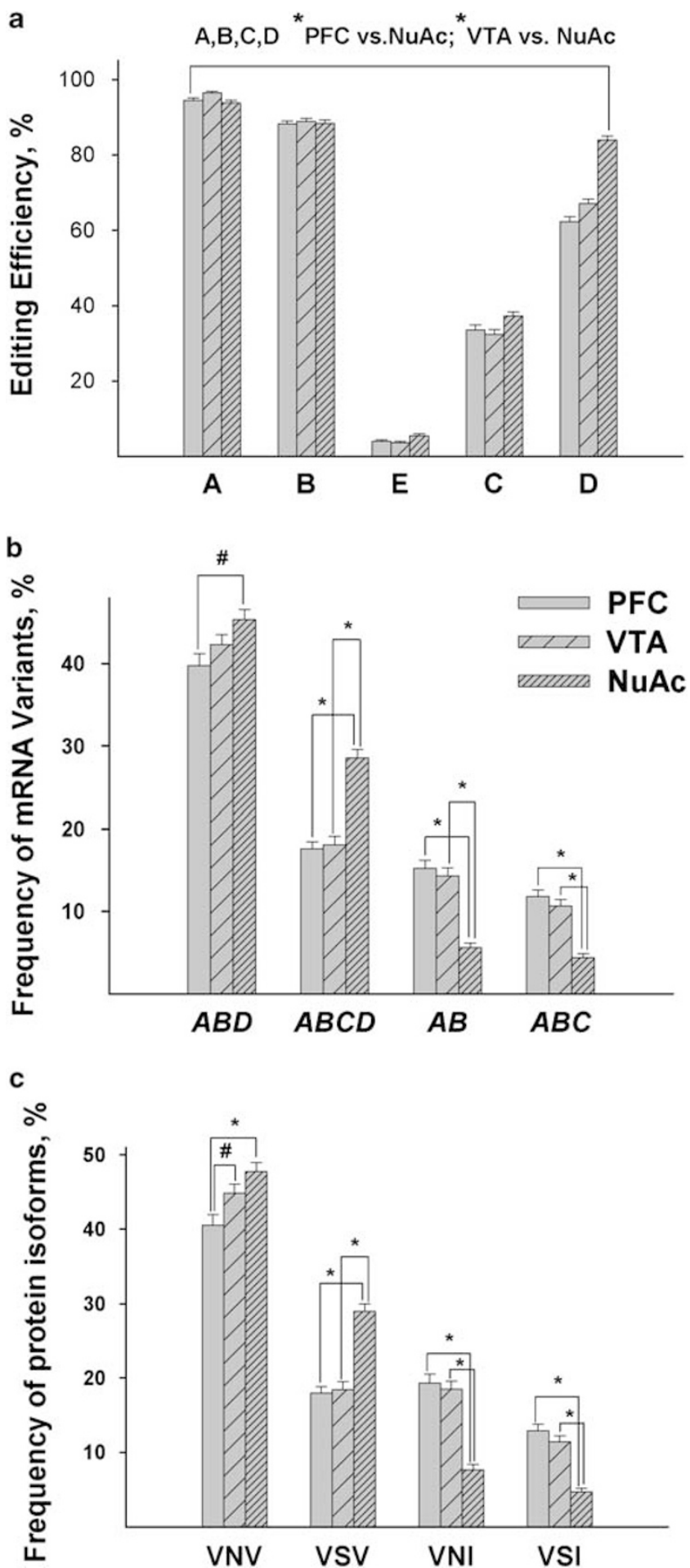

Figure 3 Regional differences of $5-\mathrm{HT}_{2} \mathrm{C}$ editing in the rat brain. Shown are means \pm SEM of editing efficiencies at the five editing sites (panel a), frequencies of the mRNA variants (panel $b$ ), and frequencies of the predicted protein isoforms (panel c) in three different brain regions. All editing parameters are compared for the entire cohort (HRs and LRs combined). Shown are only the variants and isoforms that were observed at greater than $\sim 5 \%$ frequencies $\left({ }^{\#} p<0.02 ;{ }^{*} p<0.000\right.$ I).

splice sites and also produces a non-functional truncated protein product. Two assays were employed in this study to distinguish between the transcripts that encode functional 


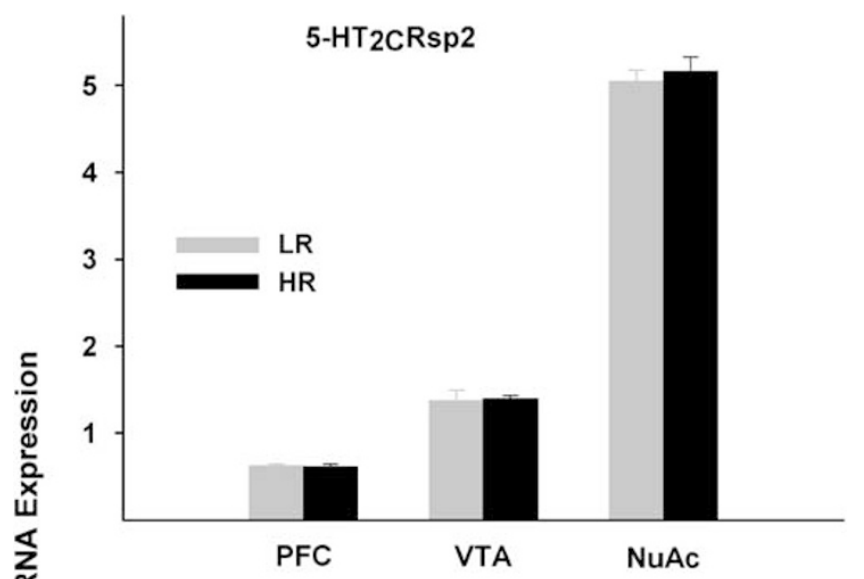

5-HT2CRsp1

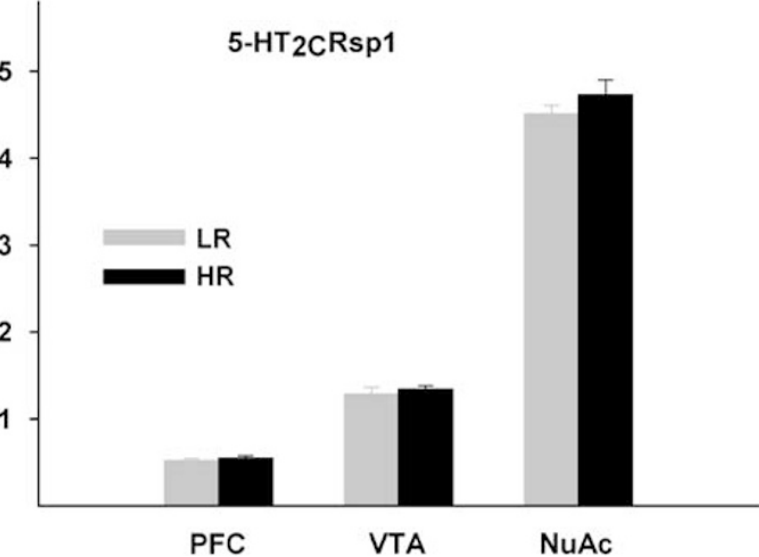

Figure 4 Analysis of $5-H_{2} \mathrm{R}$ mRNA expression. mRNA expression was measured by qPCR. Shown are means \pm SEM. $5-H_{2} T_{2} R s p 2$ and $5-H_{2} \mathrm{CRsp}$ I transcripts result from splicing at sp2 and sp/ sites and encode functional and truncated non-functional receptors, respectively. $5-\mathrm{HT}_{2} \mathrm{CRsp} 2$ and $5-\mathrm{HT}_{2} \mathrm{CRsp}$ I expression levels were significantly different between pairs of regions (all $p$-values $<0.000$ I), but did not differ between HRs and LRs in any region.

(ADAR2f) and truncated non-functional (ADAR2nonf) proteins (see Methods). The ratio between ADAR2f and ADAR1 expression levels was also analyzed.

The repeated measures analysis showed highly significant differences among regions for all transcripts and for the ADAR2f/ADAR1 ratio $\left(5-\mathrm{HT}_{2 \mathrm{C}} \mathrm{Rsp} 1, \mathrm{~F}=1115.17\right.$; d.f. $=1.47$, $46.93 ; p<0.0001 ; \quad 5-\mathrm{HT}_{2 \mathrm{C}} \mathrm{Rsp} 2, \mathrm{~F}=1086.12 ; \quad$ d.f. $=1.69$, 53.92; $p<0.0001 ;$ ADAR1, $\mathrm{F}=83.23$; d.f. $=1.85, \quad 59.14$; $p<0.0001 ; \quad$ ADAR2f, $\quad \mathrm{F}=239.89 ; \quad$ d.f. $=1.48, \quad 47.27$; $p<0.0001 ; \quad$ ADAR2nonf, $\mathrm{F}=298.94 ; \quad$ d.f. $=1.29, \quad 41.29$; $p<0.0001 ;$ ADAR2f/ADAR1 ratio, $\mathrm{F}=27.86$; d.f. $=1.79$, 57.23; $p<0.0001$ ), but the differences between HRs and LRs and phenotype-by-region interaction were not significant. Similarly, the differences between HRs and LRs were not significant in any region, but the differences between pairs of regions (PFC $v s$ NuAc shell, PFC $v s$ VTA, and VTA vs NuAc shell) were highly significant for all transcripts (5- $\mathrm{HT}_{2 \mathrm{C}} \mathrm{Rsp} 1$, all $t$-values $\geqslant 16.03$, all $p$-values $<0.0001$; $5-\mathrm{HT}_{2 \mathrm{C}} \mathrm{Rsp} 2$, all $t$-values $\geqslant 11.79$, all $p$-values $<0.0001$; ADAR1, all $t$-values $\geqslant 6.11$, all $p$-values $<0.0001$; ADAR2f, all $t$-values $\geqslant 9.96$, all $p$-values $<0.0001$; ADAR2nonf, all $t$-values $\geqslant 13.70$, all $p$-values $<0.0001$; Figures 4 and 5$)$. The ADAR2f/ADAR1 ratios were significantly different between the NuAc shell and the other two regions (all $t$-values $\geqslant 5.83$,
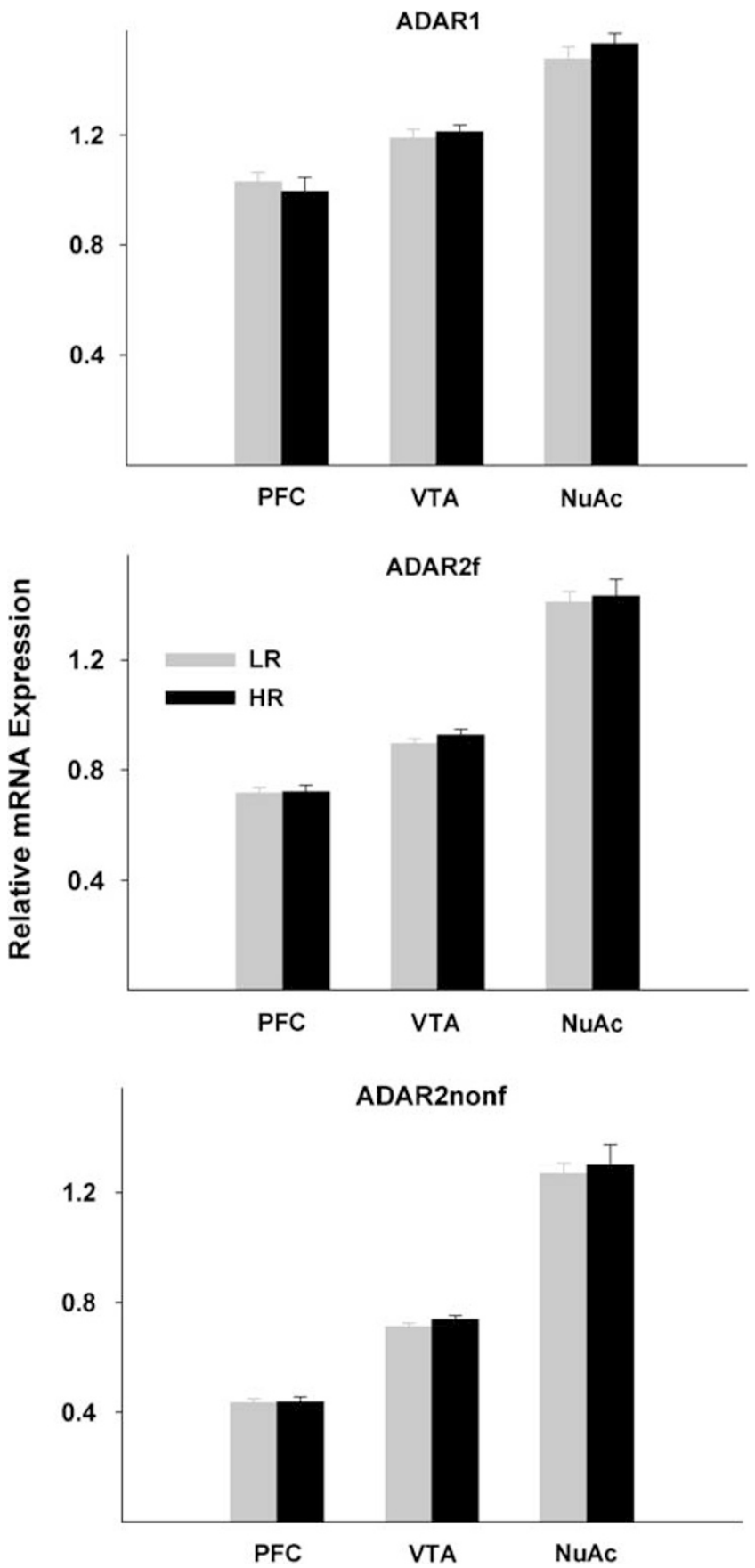

Figure 5 Analysis of ADARI and ADAR2 mRNA expression. mRNA expression was measured by GPCR. Shown are means \pm SEM. Two different TaqMan assays were employed to distinguish between the ADAR2 transcripts that encode functional (ADAR2f) and truncated nonfunctional (ADAR2nonf) proteins. ADARI, ADAR2f, and ADAR2nonf expression levels were significantly different between pairs of regions (all p-values $<0.000 \mathrm{I}$ ), but did not differ between HRs and LRs in any region.

all $p$-values $<0.0001)$, but did not differ between PFC and VTA (Figure 6).

\section{Correlations Between ADAR mRNA Expression and Editing Efficiencies}

There were no correlations between ADAR expression and editing efficiencies when the correlation analysis was 


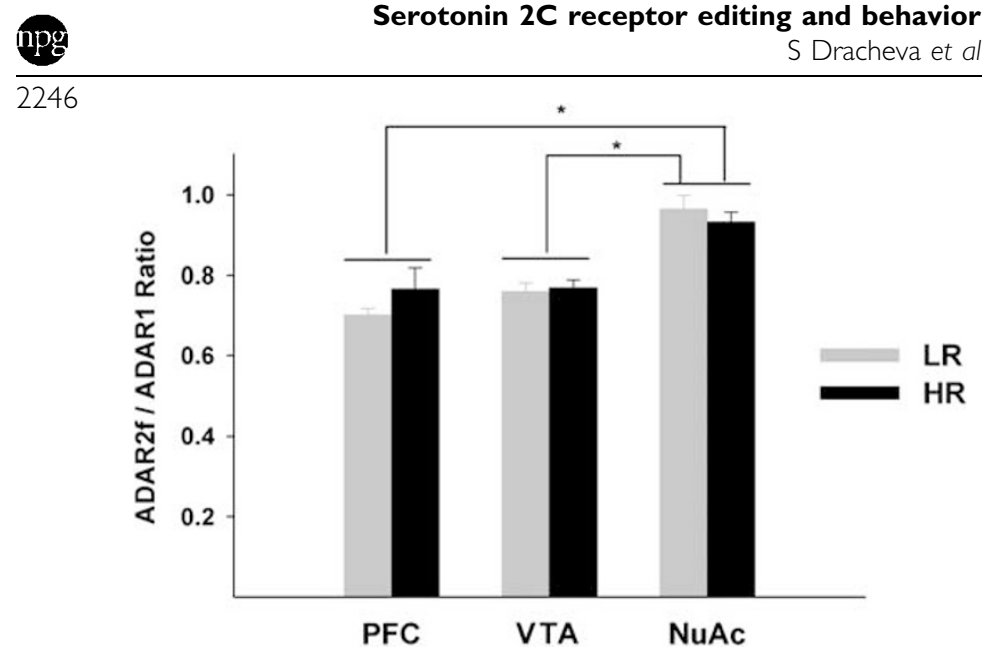

Figure 6 Ratio between ADAR2f and ADARI expression levels. Shown are means $\pm S E M$. The ratios were significantly different between the NuAc shell and the two other regions $(* p<0.000 \mathrm{I})$, but did not differ between PFC and VTA or between HRs and LRs in any region.

Table 4 Correlation Between Editing Efficiencies and ADARs mRNA Expression

\begin{tabular}{|c|c|c|c|}
\hline $\begin{array}{l}\text { Editing efficiency } \\
\text { or mRNA expression }\end{array}$ & ADARI & ADAR2f & ADAR2nonf \\
\hline \multirow{2}{*}{ A } & $r=-0.138$ & $r=-0.134$ & $r=-0.087$ \\
\hline & $p=0.147$ & $p=0.164$ & $p=0.366$ \\
\hline \multirow{2}{*}{ B } & $r=-0.070$ & $r=-0.001$ & $r=0.032$ \\
\hline & $p=0.466$ & $p=0.991$ & $p=0.737$ \\
\hline \multirow{2}{*}{ E } & $r=0.179$ & $r=0.2761$ & $r=0.244$ \\
\hline & $p=0.062$ & $p=0.004$ & $p=0.010$ \\
\hline \multirow{2}{*}{ C } & $r=0.149$ & $r=0.160$ & $r=0.170$ \\
\hline & $p=0.112$ & $p=0.096$ & $p=0.076$ \\
\hline \multirow{2}{*}{ D } & $r=0.540$ & $r=0.685$ & $r=0.712$ \\
\hline & $\mathbf{p}<000 \mathrm{I}$ & $\mathbf{p}<000 \mathrm{I}$ & $\mathbf{p}<000 \mathbf{I}$ \\
\hline \multirow{2}{*}{ ADARI } & & $r=0.862$ & $r=0.823$ \\
\hline & & $\mathbf{p}<0001$ & $p<0001$ \\
\hline \multirow{2}{*}{ ADAR2f } & & & $r=\mathbf{0 . 9 3 I}$ \\
\hline & & & $\mathbf{p}<000 \mathrm{I}$ \\
\hline
\end{tabular}

Analysis was performed across three brain regions (PFC, VTA, and NuAc) combined $(N=|| 2)$. Significant correlations $(p<0.00 \mid 2)$ are shown in bold.

performed in each individual region. However, significant correlations were observed between ADAR expression levels and the editing efficiency at site D (all $r$-values $>0.540$, all $p$-values $<0.0001)$ when the analysis was performed across all three regions combined (Table 4). In addition, strong correlations among all ADAR transcripts were detected when the analysis was performed across the regions (all $r$-values $>0.823$, all $p$-values $<0.0001$ ).

\section{DISCUSSION}

This study provides the first extensive evaluation of $5-\mathrm{HT}_{2 \mathrm{C}} \mathrm{R}$ mRNA editing in relation to addiction susceptibility. Most investigations to date had only examined $5-\mathrm{HT}_{2 \mathrm{C}} \mathrm{R}$ mRNA editing in total brain or in one brain region. Examining three brain regions provides insights into regional variations in $5-\mathrm{HT}_{2 \mathrm{C}} \mathrm{R}$ mRNA editing. Significant between-region differences in $5-\mathrm{HT}_{2 \mathrm{C}} \mathrm{R}$ editing and expression were seen, as well as an increase in editing in the PFC in HRs relative to LRs.

\section{Pattern of 5- $\mathrm{HT}_{2 \mathrm{C}} \mathrm{R}$ Editing and Expression in the Rat Brain}

Our study confirmed previous observations that, although both rat and human brains express multiple variants of $5-\mathrm{HT}_{2 \mathrm{C}} \mathrm{R}$ mRNA, the rat brain exhibits less diversity of mRNA variants (reviewed in Werry et al, 2008). Indeed, compared with our recent $5-\mathrm{HT}_{2 \mathrm{C}} \mathrm{R}$ editing analysis in the human PFC (Dracheva et al, 2008c), fewer mRNA variants, and accordingly fewer protein isoforms, were detected in rats than in humans despite the fact that we assessed more clones in the rat than in the human study (5136 and 4709 clones, respectively). Of 32 possible mRNA variants, 27 were detected in rats compared with 30 in humans. Accordingly, of 24 possible protein isoforms, 19 were predicted in rats, whereas 22 were predicted in humans. The pattern of editing was also different between humans and rats. In humans, $A B C D$ is the most frequent mRNA variant in the whole brain (Niswender et al, 1999; Fitzgerald et al, 1999; Wang et al, 2000) and in PFC (Dracheva et al, 2003; Dracheva et al, 2008c). This variant is edited at four sites and encodes the fully edited (compared with INI) VSV protein isoform (see Tables 2 and 3). In rats, $A B D$ was the most frequently expressed variant in all brain regions assessed in this study. This variant is edited at three sites and encodes the VNV isoform. Similar data have been reported for the whole rat brain (Burns et al, 1997; Niswender et al, 1999) and for the neocortex and amygdala in mice (Englander et al, 2005; Hackler et al, 2006).

Two factors could contribute to species-specific variations in the repertoire of $5-\mathrm{HT}_{2 \mathrm{C}} \mathrm{R}$ editing. First are differences in editing templates: A-to-I RNA editing is dependent on double-stranded (ds) RNA, and the efficiency of editing is determined by the secondary structure of RNA (Valente and Nishikura, 2005). $5-\mathrm{HT}_{2 \mathrm{C}} \mathrm{R}$ region of editing forms a prerequisite ds loop structure with the adjacent intron (Burns et al, 1997). Although the sequences of DNA encoding the putative stem loops are highly conserved between humans and rats $(\sim 88 \%$ identity), the predicted secondary structures of these loops differ significantly between the species (Werry et al, 2008), which may account for the observed variations in editing patterns. Second, the editing process per se may differ between the species. For example, expression and/or activity of editing enzymes (ADAR1 and/or ADAR2) and expression of small nucleolar RNA or dsRNA helicase A (that were shown to influence $5-\mathrm{HT}_{2 \mathrm{C}} \mathrm{R}$ editing) (Yang et al, 2004; Vitali et al, 2005) may vary between humans and rats. The functional consequences of $5-\mathrm{HT}_{2 \mathrm{C}} \mathrm{R}$ editing differences between the species remain to be investigated.

Our study also confirmed the regional differences in $5-\mathrm{HT}_{2 \mathrm{C}} \mathrm{R}$ editing, which were previously reported in humans and rats (Werry et al, 2008). To our knowledge, $5-\mathrm{HT}_{2 \mathrm{C}} \mathrm{R}$ editing status in the VTA and NuAc has never been investigated. No differences between the PFC and VTA were detected in the expression of the four most frequently 
observed mRNA variants $(A B D, A B C D, A B$, and $A B C)$ or in the predicted protein isoforms (VNV, VSV, VNI, and VSI). However, $5-\mathrm{HT}_{2 \mathrm{C}} \mathrm{R}$ was significantly more edited in the NuAc shell compared with both the PFC and VTA. Specifically, an approximately $30 \%$ increase of editing at the $\mathrm{D}$ site as well as a modest increase at the $\mathrm{C}$ site was observed in the NuAc shell compared with PFC and VTA. Consequently, although the frequencies of the $A B D$ mRNA variant and the VNV isoform (encoded by $A B D$ ) were only slightly increased, $A B C D$ and VSV (encoded by $A B C D$ ) were $\sim 60 \%$ higher in the NuAc shell compared with the other two regions, whereas the frequencies of the mRNA variants that are not edited at site $\mathrm{D}(A B$ and $A B C)$ and, accordingly, the frequencies of the protein isoforms encoded by these variants (VNI and VSI, respectively) were $\sim 60 \%$ lower in the NuAc shell.

The regional differences in $5-\mathrm{HT}_{2 \mathrm{C}} \mathrm{R}$ mRNA editing cannot be attributed to differences between the editing templates, as the sequence in the exon5-intron5 dsRNA stem loop that is required for editing is identical in all regions of the rat brain. Thus, the higher $5-\mathrm{HT}_{2 \mathrm{C}} \mathrm{R}$ editing efficiency in the NuAc shell compared with that in the other regions could only result from regional differences in the editing process. As the observed regional differences are largely determined by editing at the $\mathrm{D}$ site, and because editing at this site is mostly catalyzed by ADAR2 (Werry et al, 2008), the simplest explanation for these regional differences is the higher expression and/or higher activity of ADAR2 in the NuAc shell compared with that in the PFC and VTA. Indeed, our findings show higher expression of ADAR2 in the NuAc shell compared with that in the VTA and PFC. As discussed above, four different ADAR2 transcripts have been described, and those can be categorized into two categories. The first two transcripts (ADAR2f) encode functional ADAR2 proteins. The other two transcripts (ADAR2nonf) are generated by alterative splicing due to ADAR2 autoediting and encode truncated nonfunctional protein isoforms. In line with a current view that autoediting of ADAR2 regulates its endogenous level (Feng et al, 2006), we detected a strong correlation between expression levels of ADAR2f and ADAR2nonf. Consequently, both types of ADAR2 transcripts showed increased expression in the NuAc shell compared with the VTA and PFC. In addition, although there were no correlations between ADAR2 expression and editing efficiencies at any site in any individual region, significant correlations were observed between ADAR2 (both ADAR2f and ADAR2nonf) and the editing at site $\mathrm{D}$ when the analysis was performed across all regions. This pattern suggests a direct association between ADAR2 transcript levels and the efficiency of editing at this site. ADAR2 expression levels were also significantly higher in the VTA compared with those in the PFC. Accordingly, a small but significant increase of editing at site $\mathrm{D}$ was detected in the VTA compared with that in the PFC.

A number of studies have suggested that although editing at the $\mathrm{D}$ site requires ADAR2, editing at the $\mathrm{A}$ and $\mathrm{B}$ sites is totally dependent on ADAR1 (reviewed in Valente and Nishikura, 2005). A cross-talk between ADAR1 and ADAR2 activities has been observed, however, suggesting that the relative expression of different ADARs may impact the editing efficiency at different sites (Valente and Nishikura, 2005). No correlations between ADAR1 expression and editing at the A or B site were detected in our study, implying that the level of ADAR1 mRNA expression did not limit the efficiency of editing at these sites. On the contrary, a significant correlation was observed between ADAR1 and editing at the D site. As ADAR1 does not catalyze D-site editing, this correlation does not likely represent a functional association, but rather reflects strong correlations between ADAR1 and ADAR2 that were observed in our study. We also detected that the ADAR2f/ADAR1 ratio was significantly higher in the NuAc compared with the PFC and VTA (which did not differ from each other). As ADAR1 has previously been shown to inhibit ADAR2 activity (Yang et al, 2004), the increased level of editing in the NuAc (mostly at site D) probably resulted not only from increased expression of ADAR2, but also from a higher ADAR2f/ADAR1 ratio in this region compared with the PFC and VTA. These data clearly show that, as was suggested elsewhere (Werry et al, 2008), both absolute and relative levels of different ADARs are important in determining the identity and variety of the expressed $5-\mathrm{HT}_{2} \mathrm{R}$ variants in different regions (and probably in different cell populations) in the brain.

Our data also indicate that the expression of ADAR2 variants and/or ADAR2/ADAR1 ratio are imperfect predictors of editing at site D. Indeed, the observed correlations, albeit highly statistically significant, were moderate in magnitude $(r \sim 0.7)$, suggesting that editing efficiency is only partially controlled by the mRNA expression of ADARs in the brain. Thus, other factors may contribute to regional differences in $5-\mathrm{HT}_{2 \mathrm{C}} \mathrm{R}$ editing. As our regional dissections contained mixtures of different cell types, the functional association between ADAR2 and $5-\mathrm{HT}_{2 \mathrm{C}} \mathrm{R}$ editing is complicated by their cellular heterogeneity. ADAR2 is ubiquitously expressed and its expression may differ between different cell types. $5-\mathrm{HT}_{2 \mathrm{C}} \mathrm{R}$ expression, however, is restricted to specific cellular populations (see below).

\section{Implications for $5-\mathrm{HT}_{2 \mathrm{C}} \mathrm{R}$ Modulation of Dopaminergic Neurotransmission}

An important aspect of this study was the potential relevance of $5-\mathrm{HT}_{2 \mathrm{C}} \mathrm{R}$ mRNA editing to DA neurotransmission. Recent in vivo studies have shown that constitutive activity of $5-\mathrm{HT}_{2 \mathrm{C}} \mathrm{Rs}$ exerts tonic inhibitory control on DA release in the NuAc (De Deurwaerdere et al, 2004), underscoring the potential importance of ligand-independent $5-\mathrm{HT}_{2 \mathrm{C}} \mathrm{R}$ function in the modulation of reward circuitry (Berg et al, 2008). Previous studies conducted in vitro in transfected cells have shown that the unedited $5-\mathrm{HT}_{2 \mathrm{C}} \mathrm{R}$ possesses a significant degree of ligand-independent constitutive (or basal) activity, which is gradually diminished by editing (Niswender et al, 1999). Our data suggest that relative to the VTA, $5-\mathrm{HT}_{2 \mathrm{C}} \mathrm{R}$ mRNA editing in the NuAc shell is enhanced and, therefore, favors the receptor population with attenuated constitutive activity. This pattern is, however, the opposite of that previously hypothesized based on studies involving the intracranial microinjection of $5-\mathrm{HT}_{2 \mathrm{C}} \mathrm{R}$ inverse agonists to the VTA and to the NuAc shell (Navailles et al, 2006; Navailles et al, 2008). Three considerations may reconcile our findings with these pharmacological data. First, $5-\mathrm{HT}_{2 \mathrm{C}} \mathrm{R}$ mRNA expression is approximately three times higher in the NuAc shell than in the VTA. Thus, despite the prevalence of the highly edited $5-\mathrm{HT}_{2 \mathrm{C}} \mathrm{R}$ isoforms in the NuAc shell, the overall constitutive 
activity may nevertheless be higher in the NuAc shell than in the VTA because of the absolute amount of less or unedited isoforms. Second, 5- $\mathrm{HT}_{2 \mathrm{C}} \mathrm{R}$ may be expressed by different cell types in the two regions. In the $\mathrm{NuAc}, 5-\mathrm{HT}_{2 \mathrm{C}} \mathrm{R}$ transcripts appear to localize primarily to medium-sized neurons that exhibit distribution, localization, and morphology typical to striatal GABA efferent neurons (Eberle-Wang et al, 1997). Thus, $5-\mathrm{HT}_{2 \mathrm{C}} \mathrm{Rs}$ in the NuAc are likely to provide predominately negative feedback to the VTA DA neurons. Inhibition of constitutive $5-\mathrm{HT}_{2 \mathrm{C}} \mathrm{R}$ activity within the NuAc (by intracranial injection of an inverse agonist) would, therefore, increase DA release in this region (Navailles et al, 2006). In VTA, recent studies localized the $5-\mathrm{HT}_{2 \mathrm{C}} \mathrm{R}$ protein to both GABA and DA neurons (Bubar and Cunningham, 2007). $5-\mathrm{HT}_{2 \mathrm{C}} \mathrm{R}$ is excitatory (Stanford et al, 2005). Thus, its modulatory influence on DA neuron firing in the VTA (and, consequently, DA release in the NuAc) would reflect the functional balance of its opposing actions on GABA and DA neurons. Intra-VTA administration of an inverse agonist might, therefore, have no effect on DA release in the NuAc (Navailles et al, 2006). Third, recent work on mutant mice that solely express one of the two extreme editing isoforms of the receptor (INI or VGV) suggests that, as previously suggested by in vitro studies (Marion et al, 2004), the intracellular $v s$ cell surface localization of the receptor may differ between isoforms such that the ultimate functional impact (including the level of constitutive activity) of the receptors could not be unambiguously predicted by the patterns of $5-\mathrm{HT}_{2 \mathrm{C}} \mathrm{R}$ editing alone (Kawahara et al, 2008).

\section{Region-Specific Differences in $5-\mathrm{HT}_{2 \mathrm{C}} \mathrm{R}$ Editing Between HRs and LRs}

Despite the lack of differences in the expression of both $5-\mathrm{HT}_{2 \mathrm{C}} \mathrm{R}$ mRNA variants $\left(5-\mathrm{HT}_{2 \mathrm{C}} \mathrm{Rsp} 1\right.$ and $\left.5-\mathrm{HT}_{2 \mathrm{C}} \mathrm{Rsp} 2\right)$ between the behavioral phenotypes in the brain regions studied, $5-\mathrm{HT}_{2 \mathrm{C}} \mathrm{R}$ editing efficiency was higher in HRs vs LRs in the PFC. Functional activity decreases with editing; thus, this finding would predict reduced $5-\mathrm{HT}_{2 \mathrm{C}} \mathrm{R}$ function in the PFC of HRs that might be relevant for the individual differences in addiction vulnerability noted for this behavioral trait. The detected editing differences are consistent with the numerous accounts that the central $5-\mathrm{HT}_{2 \mathrm{C}} \mathrm{R}$ exerts a negative control on the psychomotorstimulant and rewarding effects of various drugs of abuse (see above).

The mechanisms and circuitry underlying the differences in the cortical $5-\mathrm{HT}_{2 \mathrm{C}} \mathrm{R}$ editing between $\mathrm{HR}$ and LR phenotypes are not easily understood, however, based on the current literature. Locomotor activity is associated with an increase in DA release in the NuAc (Dunnett and Robbins, 1992) and, compared with LRs, HRs have increased basal and stimulated DA levels in the NuAc (Hooks et al, 1992; Rouge-Pont et al, 1993). In the PFC, $5-\mathrm{HT}_{2 \mathrm{C}} \mathrm{Rs}$ are primarily localized to GABA interneurons (Liu et al, 2007) that are known to inhibit PFC glutamatergic pyramidal neurons that project to both the VTA and NuAc (Sesack and Carr, 2002). In the VTA, these glutamatergic cortical afferents synapse on GABA (but not DA) mesoaccumbens neurons (Carr and Sesack, 2000). In the $\mathrm{NuAc}$, they also synapse on GABA neurons, which, in turn, project to the VTA where they inhibit DA neurons (Sesack and Pickel, 1992). Thus, by exciting the interposed GABA neurons it would be expected that the firing of the pyramidal PFC neurons would inhibit mesoaccumbens DA neurons. Consistent with the expected anatomical organization, several, but not all (see (Karreman and Moghaddam, 1996)), neurophysiological studies have shown that the firing of PFC glutamatergic neurons inhibits DA release in the NuAc (Jackson et al, 2001). Unless countered by other modulatory influences, stimulation of $5-\mathrm{HT}_{2 \mathrm{C}} \mathrm{Rs}$ in the PFC might, therefore, be expected to reduce glutamate output within the mesoaccumbens system, leading to an increase of accumbal DA outflow. This increased DA release in the $\mathrm{NuAc}$ might then be expected to increase locomotion.

Our findings of enhanced editing (and presumably reduced function) of $5-\mathrm{HT}_{2 \mathrm{C}} \mathrm{Rs}$ in the PFC of HRs vs LRs are at variance with the above speculation. Moreover, other studies that have evaluated the influence of the PFC $5-\mathrm{HT}_{2 \mathrm{C}} \mathrm{R}$ function on the mesoaccumbens system have reported complex and seemingly contradictory results. Specifically, although an earlier study suggested that cortical $5-\mathrm{HT}_{2 \mathrm{C}} \mathrm{Rs}$ exert negative control over behavioral responses induced by cocaine (Filip and Cunningham, 2003), a recent study reported that those receptors enhance cocaine-evoked DA efflux in the NuAc (Leggio et al, 2008).

These apparent contradictions might be explained by the influence of cortical $5-\mathrm{HT}_{2 \mathrm{C}} \mathrm{Rs}$ on additional circuits that regulate accumbal DA release. Indeed, it is known that glutamatergic synapses of subcortical origin in the VTA significantly outnumber those of cortical origin (Omelchenko and Sesack, 2007). Moreover, some of these glutamatergic afferents to the VTA originate from other regions, including the hypothalamus, thalamus, and brainstem, which themselves receive PFC glutamatergic input (Sesack et al, 2003; Pinto et al, 2003; Geisler and Zahm, 2005; Omelchenko and Sesack, 2007; Geisler et al, 2007). Regulation of mesoaccumbens DAergic activity by the PFC may, therefore, involve polysynaptic glutamatergic inputs to the VTA from multiple sources. Thus, the control of the accumbal DA outflow by the PFC 5- $\mathrm{HT}_{2 \mathrm{C}} \mathrm{Rs}$ may involve a functional balance between GABA- and glutamate-mediated influences. More research is needed to clarify the mechanisms and circuitry underlying this interaction.

Individual variation in the $\mathrm{PFC} 5-\mathrm{HT}_{2} \mathrm{C}$ editing (and, therefore, function) is likely to influence the liability to a variety of psychiatrically relevant phenomena including substance abuse. Early studies detected reduced tissue content of 5-HT and its metabolite (5-HIAA) in the PFC and $\mathrm{NuAc}$ of HRs compared with LRs (Piazza et al, 1991). Lower cortical (but not accumbal) 5-HT was subsequently confirmed in HRs vs LRs in Thiel et al (1999), suggesting decreased serotonergic function in the PFC of HRs. It is, therefore, tempting to speculate that the differences in the PFC $5-\mathrm{HT}_{2 \mathrm{C}} \mathrm{R}$ editing detected in this study may stem from variations in the PFC 5-HT between the phenotypes. Interestingly, we recently detected increased $5-\mathrm{HT}_{2 \mathrm{C}} \mathrm{R}$ editing (manifested as increased frequency of the VSV isoform) in PFC in suicide victims (Dracheva et al, 2008c). This difference was specific to suicide and was not associated with the comorbid psychiatric diagnoses (bipolar disorder or schizophrenia), demographic characteristics (e.g., age and sex), or prescribed psychoactive medications. The $5-\mathrm{HT}_{2 \mathrm{C}} \mathrm{R}$ editing differences in suicide had been previously suggested in other reports (Niswender et al, 2001; 
Gurevich et al, 2002). It is worth noting that numerous studies suggested decreased serotonergic function in the brain of suicide victims, including 5-HT-related abnormalities in the PFC (Mann, 2003). Accordingly, the enhanced level of the fully edited VSV isoform in the PFC (which is the most frequent $5-\mathrm{HT}_{2 \mathrm{C}} \mathrm{R}$ isoform in the human and one of the four most frequent isoforms in the rat PFC) may be associated with vulnerability to drug addiction and suicide. There is in fact a high degree of correlation between these disorders, and drug addiction is considered a risk factor for suicidal behavior (Arsenault-Lapierre et al, 2004). It is important to recognize, however, that the exact contribution of the PFC $5-\mathrm{HT}_{2 \mathrm{C}} \mathrm{R}$ editing to interindividual vulnerability remains to be determined, as HRs differ from LRs not only in regard to reward sensitivity and goal-directed behavior (Marinelli, 2005), but also in their ability to learn operant tasks (Mitchell et al, 2005), as well as in their emotional reactivity (Stead $e t$ al, 2006). Specifically, HRs show less anxiety in novel contexts than LRs, which appears to be consistent with the differences in neuroendocrine function and in the regulation of the serotonergic system between the phenotypes (Kabbaj et al, 2000; White et al, 2007; Mallo et al, 2008).

In summary, our study revealed distinct differences of 5- $\mathrm{HT}_{2 \mathrm{C}} \mathrm{R}$ mRNA expression and editing among brain regions that comprise key components of the mesocorticolimbic system that imply significant differences in functional activity (including the levels of constitutive activity) among $5-\mathrm{HT}_{2} \mathrm{R}$ neuronal populations within this circuitry. Moreover, the data indicate that these regional differences in editing may, at least in part, arise from the differences in expression levels of the editing enzyme, ADAR2. The discrete specificity of $5-\mathrm{HT}_{2 \mathrm{C}} \mathrm{R}$ editing disturbance observed within the mesocorticolimbic neuronal populations between the HR and LR behavioral phenotypes significantly implicates the PFC in the pathophysiology of drug abuse liability.

\section{ACKNOWLEDGEMENTS}

This work was supported by the National Institute on Drug Abuse grant DA022264 (SD), the VISN3 Mental Illness Research and Education Clinical Center (SD) and the use of facilities at the JJ Peters VA Medical Center, Bronx, NY where SD and YH are Research Health Science Specialists and WB is a Staff Physician. We are grateful to Ms Nayna Patel and Mr Benjamin Chin for their superb technical assistance.

\section{DISCLOSURE/CONFLICT OF INTEREST}

The authors declare that, except for income received from their primary employers, no financial support or compensation has been received from any individual or corporate entity over the past 3 years for research or professional service, and there are no personal financial holdings that could be perceived as constituting a potential conflict of interest.

\section{REFERENCES}

Arsenault-Lapierre G, Kim C, Turecki G (2004). Psychiatric diagnoses in 3275 suicides: a meta-analysis. BMC Psychiatry 4: 37 .
Bass BL (2002). RNA editing by adenosine deaminases that act on RNA. Annu Rev Biochem 71: 817-846.

Berg KA, Clarke WP, Cunningham KA, Spampinato U (2008). Fine-tuning serotonin(2c) receptor function in the brain: molecular and functional implications. Neuropharmacology 55: 969-976.

Berg KA, Cropper JD, Niswender CM, Sanders-Bush E, Emeson RB, Clarke WP (2001). RNA-editing of the 5-HT(2C) receptor alters agonist-receptor-effector coupling specificity. $\mathrm{Br} J$ Pharmacol 134: 386-392.

Bubar MJ, Cunningham KA (2007). Distribution of serotonin 5 -HT2C receptors in the ventral tegmental area. Neuroscience 146: 286-297.

Burns CM, Chu H, Rueter SM, Hutchinson LK, Canton H, Sanders-Bush E et al (1997). Regulation of serotonin-2C receptor G-protein coupling by RNA editing. Nature 387: 303-308.

Canton H, Emeson RB, Barker EL, Backstrom JR, Lu JT, Chang MS et al (1996). Identification, molecular cloning, and distribution of a short variant of the 5-hydroxytryptamine2C receptor produced by alternative splicing. Mol Pharmacol 50: 799-807.

Carr DB, Sesack SR (2000). GABA-containing neurons in the rat ventral tegmental area project to the prefrontal cortex. Synapse 38: 114-123.

De Deurwaerdere P, Navailles S, Berg KA, Clarke WP, Spampinato $\mathrm{U}$ (2004). Constitutive activity of the serotonin2C receptor inhibits in vivo dopamine release in the rat striatum and nucleus accumbens. J Neurosci 24: 3235-3241.

de Wit H, Uhlenhuth EH, Johanson CE (1986). Individual differences in the reinforcing and subjective effects of amphetamine and diazepam. Drug Alcohol Depend 16: 341-360.

Di Giovanni G, Di M, V, Esposito E (2002). Serotonin/dopamine interaction-focus on 5-HT2C receptor, a new target of psychotropic drugs. Indian J Exp Biol 40: 1344-1352.

Di Matteo V, Pierucci M, Esposito E (2004). Selective stimulation of serotonin $2 \mathrm{c}$ receptors blocks the enhancement of striatal and accumbal dopamine release induced by nicotine administration. J Neurochem 89: 418-429.

Dracheva S, Byne W, Chin B, Haroutunian V (2008a). Ionotropic glutamate receptor mRNA expression in the human thalamus: absence of change in schizophrenia. Brain Res 1214: 23-34.

Dracheva S, Chin B, Haroutunian V (2008b). Altered serotonin 2C receptor RNA splicing in suicide: association with editing. NeuroReport 19: 379-382.

Dracheva S, Elhakem SL, Marcus SM, Siever LJ, McGurk SR, Haroutunian V (2003). RNA editing and alternative splicing of human serotonin $2 \mathrm{C}$ receptor in schizophrenia. J Neurochem 87: 1402-1412.

Dracheva S, Patel N, Woo DA, Marcus SM, Siever LJ, Haroutunian $\mathrm{V}$ (2008c). Increased serotonin 2C receptor mRNA editing: a possible risk factor for suicide. Mol Psychiatry 13: 1001-1010.

Dunnett SB, Robbins TW (1992). The functional role of mesotelencephalic dopamine systems. Biol Rev Camb Philos Soc 67: 491-518.

Eberle-Wang K, Mikeladze Z, Uryu K, Chesselet MF (1997). Pattern of expression of the serotonin $2 \mathrm{C}$ receptor messenger RNA in the basal ganglia of adult rats. J Comp Neurol 384: 233-247.

Englander MT, Dulawa SC, Bhansali P, Schmauss C (2005). How stress and fluoxetine modulate serotonin $2 \mathrm{C}$ receptor pre-mRNA editing. J Neurosci 25: 648-651.

Everitt BJ, Robbins TW (2005). Neural systems of reinforcement for drug addiction: from actions to habits to compulsion. Nat Neurosci 8: 1481-1489.

Feng Y, Sansam CL, Singh M, Emeson RB (2006). Altered RNA editing in mice lacking ADAR2 autoregulation. Mol Cell Biol 26: 480-488.

Filip M, Cunningham KA (2003). Hyperlocomotive and discriminative stimulus effects of cocaine are under the control of 
serotonin(2C) (5-HT(2C)) receptors in rat prefrontal cortex. J Pharmacol Exp Ther 306: 734-743.

Fitzgerald LW, Iyer G, Conklin DS, Krause CM, Marshall A, Patterson JP et al (1999). Messenger RNA editing of the human serotonin 5-HT2C receptor. Neuropsychopharmacology 21: 82S-90S.

Fletcher PJ, Grottick AJ, Higgins GA (2002). Differential effects of the 5-HT(2A) receptor antagonist M100907 and the 5-HT(2C) receptor antagonist SB242084 on cocaine-induced locomotor activity, cocaine self-administration and cocaine-induced reinstatement of responding. Neuropsychopharmacology 27: 576-586.

Flomen R, Knight J, Sham P, Kerwin R, Makoff A (2004). Evidence that RNA editing modulates splice site selection in the 5-HT2C receptor gene. Nucleic Acids Res 32: 2113-2122.

Geisler S, Derst C, Veh RW, Zahm DS (2007). Glutamatergic afferents of the ventral tegmental area in the rat. J Neurosci 27: 5730-5743.

Geisler S, Zahm DS (2005). Afferents of the ventral tegmental area in the rat-anatomical substratum for integrative functions. J Comp Neurol 490: 270-294.

Giorgetti M, Tecott LH (2004). Contributions of 5-HT(2C) receptors to multiple actions of central serotonin systems. Eur J Pharmacol 488: 1-9.

Gobert A, Rivet JM, Lejeune F, Newman-Tancredi A, AdhumeauAuclair A, Nicolas JP et al (2000). Serotonin(2C) receptors tonically suppress the activity of mesocortical dopaminergic and adrenergic, but not serotonergic, pathways: a combined dialysis and electrophysiological analysis in the rat. Synapse 36: 205-221.

Grottick AJ, Corrigall WA, Higgins GA (2001). Activation of $5-\mathrm{HT}(2 \mathrm{C})$ receptors reduces the locomotor and rewarding effects of nicotine. Psychopharmacology (Berl) 157: 292-298.

Gurevich I, Tamir H, Arango V, Dwork AJ, Mann JJ, Schmauss C (2002). Altered editing of serotonin $2 \mathrm{C}$ receptor pre-mRNA in the prefrontal cortex of depressed suicide victims. Neuron 34: 349-356.

Hackler EA, Airey DC, Shannon CC, Sodhi MS, Sanders-Bush E (2006). 5-HT(2C) receptor RNA editing in the amygdala of C57BL/6J, DBA/2J, and BALB/cJ mice. Neurosci Res 55: 96-104.

Hedeker D, Gibbons RD (1996). MIXOR: a computer program for mixed-effects ordinal regression analysis. Comput Methods Programs Biomed 49: 157-176.

Herrick-Davis K, Grinde E, Niswender CM (1999). Serotonin 5-HT2C receptor RNA editing alters receptor basal activity: implications for serotonergic signal transduction. J Neurochem 73: 1711-1717.

Hooks MS, Colvin AC, Juncos JL, Justice Jr JB (1992). Individual differences in basal and cocaine-stimulated extracellular dopamine in the nucleus accumbens using quantitative microdialysis. Brain Res 587: 306-312.

Jackson ME, Frost AS, Moghaddam B (2001). Stimulation of prefrontal cortex at physiologically relevant frequencies inhibits dopamine release in the nucleus accumbens. J Neurochem 78: 920-923.

Kabbaj M, Devine DP, Savage VR, Akil H (2000). Neurobiological correlates of individual differences in novelty-seeking behavior in the rat: differential expression of stress-related molecules. J Neurosci 20: 6983-6988.

Karreman M, Moghaddam B (1996). The prefrontal cortex regulates the basal release of dopamine in the limbic striatum: an effect mediated by ventral tegmental area. J Neurochem 66: 589-598.

Kawahara Y, Grimberg A, Teegarden S, Mombereau C, Liu S, Bale TL et al (2008). Dysregulated editing of serotonin 2C receptor mRNAs results in energy dissipation and loss of fat mass. J Neurosci 28: 12834-12844.

Leggio GM, Cathala A, Moison D, Cunningham KA, Piazza PV, Spampinato U (2008). Serotonin(2C) receptors in the medial prefrontal cortex facilitate cocaine-induced dopamine release in the rat nucleus accumbens. Neuropharmacology, 2009 56: 507-513.

Liu S, Bubar MJ, Lanfranco MF, Hillman GR, Cunningham KA (2007). Serotonin2C receptor localization in GABA neurons of the rat medial prefrontal cortex: implications for understanding the neurobiology of addiction. Neuroscience 146: 1677-1688.

Mallo T, Koiv K, Koppel I, Raudkivi K, Uustare A, Rinken A et al (2008). Regulation of extracellular serotonin levels and brainderived neurotrophic factor in rats with high and low exploratory activity. Brain Res 1194: 110-117.

Mann JJ (2003). Neurobiology of suicidal behaviour. Nat Rev Neurosci 4: 819-828.

Marinelli M (2005). The many facets of the locomotor response to a novel environment test: theoretical comment on Mitchell, Cunningham, and Mark (2005). Behav Neurosci 119: 1144-1151.

Marinelli M, White FJ (2000). Enhanced vulnerability to cocaine self-administration is associated with elevated impulse activity of midbrain dopamine neurons. J Neurosci 20: 8876-8885.

Marion S, Weiner DM, Caron MG (2004). RNA editing induces variation in desensitization and trafficking of 5-hydroxytryptamine 2c receptor isoforms. J Biol Chem 279: 2945-2954.

Mitchell JM, Cunningham CL, Mark GP (2005). Locomotor activity predicts acquisition of self-administration behavior but not cocaine intake. Behav Neurosci 119: 464-472.

Moro O, Lameh J, Hogger P, Sadee W (1993). Hydrophobic amino acid in the i2 loop plays a key role in receptor-G protein coupling. J Biol Chem 268: 22273-22276.

Navailles S, De Deurwaerdere P, Porras G, Spampinato U (2004). In vivo evidence that 5 -HT2C receptor antagonist but not agonist modulates cocaine-induced dopamine outflow in the rat nucleus accumbens and striatum. Neuropsychopharmacology 29: 319-326.

Navailles S, Moison D, Cunningham KA, Spampinato U (2008). Differential regulation of the mesoaccumbens dopamine circuit by serotonin2C receptors in the ventral tegmental area and the nucleus accumbens: an in vivo microdialysis study with cocaine. Neuropsychopharmacology 33: 237-246.

Navailles S, Moison D, Ryczko D, Spampinato U (2006). Regiondependent regulation of mesoaccumbens dopamine neurons in vivo by the constitutive activity of central serotonin $2 \mathrm{C}$ receptors. J Neurochem 99: 1311-1319.

Niswender CM, Copeland SC, Herrick-Davis K, Emeson RB, Sanders-Bush E (1999). RNA editing of the human serotonin 5-hydroxytryptamine $2 \mathrm{C}$ receptor silences constitutive activity. J Biol Chem 274: 9472-9478.

Niswender CM, Herrick-Davis K, Dilley GE, Meltzer HY, Overholser JC, Stockmeier CA et al (2001). RNA editing of the human serotonin 5-HT2C receptor. alterations in suicide and implications for serotonergic pharmacotherapy. Neuropsychopharmacology 24: 478-491.

Omelchenko N, Sesack SR (2007). Glutamate synaptic inputs to ventral tegmental area neurons in the rat derive primarily from subcortical sources. Neuroscience 146: 1259-1274.

Peirson SN, Butler JN, Foster RG (2003). Experimental validation of novel and conventional approaches to quantitative real-time PCR data analysis. Nucleic Acids Res 31: e73.

Piazza PV, Deminiere JM, Le Moal M, Simon H (1989). Factors that predict individual vulnerability to amphetamine self-administration. Science 245: 1511-1513.

Piazza PV, Deroche V, Rouge-Pont F, Le Moal M (1998). Behavioral and biological factors associated with individual vulnerability to psychostimulant abuse. NIDA Res Monogr 169: 105-133.

Piazza PV, Rouge-Pont F, Deminiere JM, Kharoubi M, Le Moal M, Simon H (1991). Dopaminergic activity is reduced in the prefrontal cortex and increased in the nucleus accumbens of rats predisposed to develop amphetamine self-administration. Brain Res 567: 169-174. 
Pierre PJ, Vezina P (1997). Predisposition to self-administer amphetamine: the contribution of response to novelty and prior exposure to the drug. Psychopharmacology (Berl) 129: 277-284.

Pinto A, Jankowski M, Sesack SR (2003). Projections from the paraventricular nucleus of the thalamus to the rat prefrontal cortex and nucleus accumbens shell: ultrastructural characteristics and spatial relationships with dopamine afferents. J Comp Neurol 459: 142-155.

Quirk K, Lawrence A, Jones J, Misra A, Harvey V, Lamb $\mathrm{H}$ et al (2001). Characterisation of agonist binding on human 5-HT2C receptor isoforms. Eur J Pharmacol 419: 107-112.

Roth BL (1994). Multiple serotonin receptors: clinical and experimental aspects. Ann Clin Psychiatry 6: 67-78.

Rouge-Pont F, Piazza PV, Kharouby M, Le Moal M, Simon H (1993). Higher and longer stress-induced increase in dopamine concentrations in the nucleus accumbens of animals predisposed to amphetamine self-administration. A microdialysis study. Brain Res 602: 169-174.

Rueter SM, Dawson TR, Emeson RB (1999). Regulation of alternative splicing by RNA editing. Nature 399: 75-80.

Schmauss C, Howe JR (2002). RNA editing of neurotransmitter receptors in the mammalian brain. Sci STKE 2002: E26.

Sesack SR, Carr DB (2002). Selective prefrontal cortex inputs to dopamine cells: implications for schizophrenia. Physiol Behav 77: 513-517.

Sesack SR, Carr DB, Omelchenko N, Pinto A (2003). Anatomical substrates for glutamate-dopamine interactions: evidence for specificity of connections and extrasynaptic actions. Ann NY Acad Sci 1003: 36-52.

Sesack SR, Pickel VM (1992). Prefrontal cortical efferents in the rat synapse on unlabeled neuronal targets of catecholamine terminals in the nucleus accumbens septi and on dopamine neurons in the ventral tegmental area. J Comp Neurol 320: 145-160.

Sodhi MS, Airey DC, Lambert W, Burnet PW, Harrison PJ, Sanders-Bush E (2005). A rapid new assay to detect RNA editing reveals antipsychotic-induced changes in serotonin-2C transcripts. Mol Pharmacol 68: 711-719.

Stanford IM, Kantaria MA, Chahal HS, Loucif KC, Wilson CL (2005). 5-Hydroxytryptamine induced excitation and inhibition in the subthalamic nucleus: action at 5-HT(2C), 5- HT(4) and 5-HT(1A) receptors. Neuropharmacology 49: 1228-1234.
Stead JD, Clinton S, Neal C, Schneider J, Jama A, Miller S et al (2006). Selective breeding for divergence in novelty-seeking traits: heritability and enrichment in spontaneous anxietyrelated behaviors. Behav Genet 36: 697-712.

Thiel CM, Muller CP, Huston JP, Schwarting RK (1999). High versus low reactivity to a novel environment: behavioural, pharmacological and neurochemical assessments. Neuroscience 93: 243-251.

Tomkins DM, Joharchi N, Tampakeras M, Martin JR, Wichmann J, Higgins GA (2002). An investigation of the role of 5-HT(2C) receptors in modifying ethanol self-administration behaviour. Pharmacol Biochem Behav 71: 735-744.

Valente L, Nishikura K (2005). ADAR gene family and A-to-I RNA editing: diverse roles in posttranscriptional gene regulation. Prog Nucleic Acid Res Mol Biol 79: 299-338.

Vandesompele J, De Preter K, Pattyn F, Poppe B, Van Roy N, De Paepe A et al (2002). Accurate normalization of real-time quantitative RT-PCR data by geometric averaging of multiple internal control genes. Genome Biol 3: RESEARCH0034.

Vitali P, Basyuk E, Le Meur E, Bertrand E, Muscatelli F, Cavaille J et al (2005). ADAR2-mediated editing of RNA substrates in the nucleolus is inhibited by C/D small nucleolar RNAs. J Cell Biol 169: 745-753.

Volkow ND, Fowler JS, Wang GJ (2002). Role of dopamine in drug reinforcement and addiction in humans: results from imaging studies. Behav Pharmacol 13: 355-366.

Wang Q, O'Brien PJ, Chen CX, Cho DS, Murray JM, Nishikura K (2000). Altered G protein-coupling functions of RNA editing isoform and splicing variant serotonin $2 \mathrm{C}$ receptors. J Neurochem 74: $1290-1300$.

Werry TD, Loiacono R, Sexton PM, Christopoulos A (2008). RNA editing of the serotonin 5HT2C receptor and its effects on cell signalling, pharmacology and brain function. Pharmacol Ther 119: 7-23.

White DA, Kalinichev M, Holtzman SG (2007). Locomotor response to novelty as a predictor of reactivity to aversive stimuli in the rat. Brain Res 1149: 141-148.

Yang W, Wang Q, Kanes SJ, Murray JM, Nishikura K (2004). Altered RNA editing of serotonin 5-HT2C receptor induced by interferon: implications for depression associated with cytokine therapy. Brain Res Mol Brain Res 124: 70-78. 